\title{
THE JOURNAL OF GEOLOGY
}

\section{May 1987}

\section{GEOCHEMICAL CONSEQUENCES OF MELT PERCOLATION: THE UPPER MANTLE AS A CHROMATOGRAPHIC COLUMN ${ }^{1}$}

\author{
ODED NAVON AND EDWARD STOLPER \\ Division of Geological and Planetary Sciences, California Institute of Technology, Pasadena, CA 91125
}

\section{ABSTRACT}

As magmas rise toward the surface, they traverse regions of the mantle and crust with which they are not in equilibrium; to the extent that time and the intimacy of their physical contact permit, the melts and country rocks will interact chemically. We have modeled aspects of these chemical interactions in terms of ion-exchange processes similar to those operating in simple chromatographic columns. The implications for trace element systematics are straightforward: the composition of melt emerging from the top of the column evolves from close to that of the incipient melt of the column matrix toward that of the melt introduced into the base of the column. The rate of evolution is faster in the incompatible than the compatible elements and, as a result, the abundance ratios of elements of different compatibilities can vary considerably with time. If diffusion and other dispersive processes in the melt are negligible and if exchange between melt and solid rock is rapid, extreme fractionations may occur, and the change from initial to final concentration for each element can be through an abrupt concentration front. Integration and mixing of the column output in a magma chamber or dispersive processes within the column, in particular the incomplete equilibration between matrix and fluid due to the slow diffusion in the solid phases, may lead to diffuse fronts and smooth trace element abundance patterns in the column output. If the matrix material is not replenished, the chromatographic process is a transient phenomenon. In some geological situations (e.g., under island arcs and oceanic islands), fresh matrix may be fed continuously into the column, leading to the evolution of a steady state. Aspects of the geochemistry of ultramafic rocks, island arc lavas, and comagmatic alkaline and tholeiitic magmas may be explained by the operation of chromatographic columns.

\section{INTRODUCTION}

The importance of permeable flow during segregation and migration of melts in the earth's mantle has been emphasized in a number of recent publications (e.g., Walker et al. 1978; Stolper et al. 1981; McKenzie 1984, 1985; Richter and McKenzie 1984; Scott and Stevenson 1984, 1986; Ribe 1985). Chemical interactions must occur as melts and other fluids flow through mantle rocks with which they are not initially in equilibrium. The consequences of this interaction

\footnotetext{
${ }^{1}$ Manuscript received August 4, 1986; accepted December 1, 1986.

[Journal of Geology, 1987, vol. 95, p. 285-307] (C) 1987 by The University of Chicago. All rights reserved.

0022-1376/87/9503-006\$1.00
}

have been anticipated in general terms in many discussions of the evolution of alkaline basalts (e.g., Harris 1957; Green and Ringwood 1967; Hart and Allegre 1980) and KREEP-rich lunar basalts (e.g., Warren and Wasson 1979) and in considerations of the role of mantle metasomatism in influencing the compositions of melts and mantle-derived nodules (e.g., Boettcher and O'Neil 1980; Menzies 1985). Recently, Richter (1986) examined the evolution of trace elements during the segregation of melts from their compacting source regions. The goal of this paper, prompted by the recent progress in understanding the fluid dynamical aspects of porous flow through a deformable matrix, is to consider in specific terms some of the geochemical consequences of the percolation of melts and other fluids through mantle regions with which they are not in equilibrium. 
The essence of our treatment of meltmantle interaction can be visualized by thinking about the well-known ion-exchange column. Fluid is continuously fed into the base of a column and percolates upward at a constant rate. The fluid is initially out of equilibrium with the column matrix, but as it flows upward, it interacts with the matrix and trends toward equilibrium with the initial matrix. After a time, the column becomes "dirty" or "used-up" and the fluid introduced at the base passes through the column with no interaction. Each element behaves differently during the fluid-matrix interaction, and hence fractionation can occur. The extreme fractionation possible via this kind of process is the reason that ion-exchange columns are so useful in laboratory settings. Both in the laboratory and in the mantle, the principal factors influencing the operation of the column with respect to each element include: its partition coefficient between melt and matrix, the fluid fraction, the column length, the flow rate, the grain size, and the diffusion coefficients in the fluid and the matrix. Such modeling has been previously applied to the study of metasomatic processes in crustal rocks (Korzhinskii 1970; Hofmann 1972) and to hydrothermal systems (Norton and Taylor 1979).

In this paper, we model the operation of a mantle "chromatographic column" using the laboratory column as a conceptual guide. We examine the evolution of trace element abundance patterns (TEAPs) in fluid and matrix during percolation, the kinds of fractionations that can occur, and their dependences on column parameters. In the first part of the paper we establish the "rules" that such a process will obey and examine some of the ways in which the products of such a column might be identified and distinguished from other fractionation processes. In the second half of the paper, we apply our modeling to three specific scenarios and show how chromatographic processes of the sort we have modeled may contribute to real rock suites. We emphasize at the outset, however, that even if this process operates in nature, it will surely do so in conjunction with many other processes (e.g., variable degrees of partial melting, crystallization, mixing, and assimilation). Thus, our treatment should be regarded as an effort to establish some of the end member effects of this process rather than a spe- cific model of the detailed evolution of any igneous suite. Only by understanding such end members can we begin to decipher the complexities of petrogenesis.

\section{THE IDEAL COLUMN}

Imagine a mantle region containing solid rock in which fluid forms an interconnected network along grain boundaries. Properties of interest are assumed to change over a length scale that is large compared with the matrix grain size, so matrix and fluid are treated as two interacting continua. We assume that all solid phases can be represented by some average grain size and average trace element diffusivities. Major elements are not considered, and the partition coefficients for the trace elements are taken to be constants. The assumption of uniform and constant fluid fraction is equivalent to assuming either the percolation of fluid into a dry column in which the needed porosity is instantaneously established, or the preexistence of fluid in equilibrium with the matrix. Mathematically, the only difference between these two alternatives is the addition/omission of the fluid volume initially present in the column.

Consider a representative elemental volume (Bear 1972), small compared to the scale over which the average chemical and physical variables change, and large compared to the grain size. The elemental volume consists of a solid fraction of density $\rho_{s}$ where the concentration of a trace element $i$ is $C_{s, i}$, and a fluid fraction, $\phi$, of density $\rho_{f}$ where $i$ is present in concentration $C_{f, i}$. Let $\bar{V}_{s}$ and $\bar{V}_{f}$ be the flow velocities of the solid and the fluid respectively, and let $\bar{D}_{s, i}$ and $\bar{D}_{f, i}$ be the diffusion coefficients of $i$ in the two phases; then the equation describing the conservation of mass of $i$ in the system is:

$$
\begin{gathered}
\frac{\partial}{\partial t}\left[\phi \rho_{f} C_{f, i}\right]+\frac{\partial}{\partial t}\left[(1-\phi) \rho_{s} C_{s, i}\right] \\
+\bar{V}_{f} \bar{\nabla}\left[\phi \rho_{f} C_{f, i}\right]+\bar{V}_{s} \bar{\nabla}\left[(1-\phi) \rho_{s} C_{s, i}\right] \\
-\bar{\nabla}\left[\phi \rho_{f} \bar{D}_{f, i} \bar{\nabla} C_{f, i}\right] \\
-\bar{\nabla}\left[(1-\phi) \rho_{s} \bar{D}_{s, i} \bar{\nabla} C_{s, i}\right]=0
\end{gathered}
$$

(Bear 1972; McKenzie 1984). The symbols used in our equations are summarized in table 1 for reference. 
TABLE 1

Notation

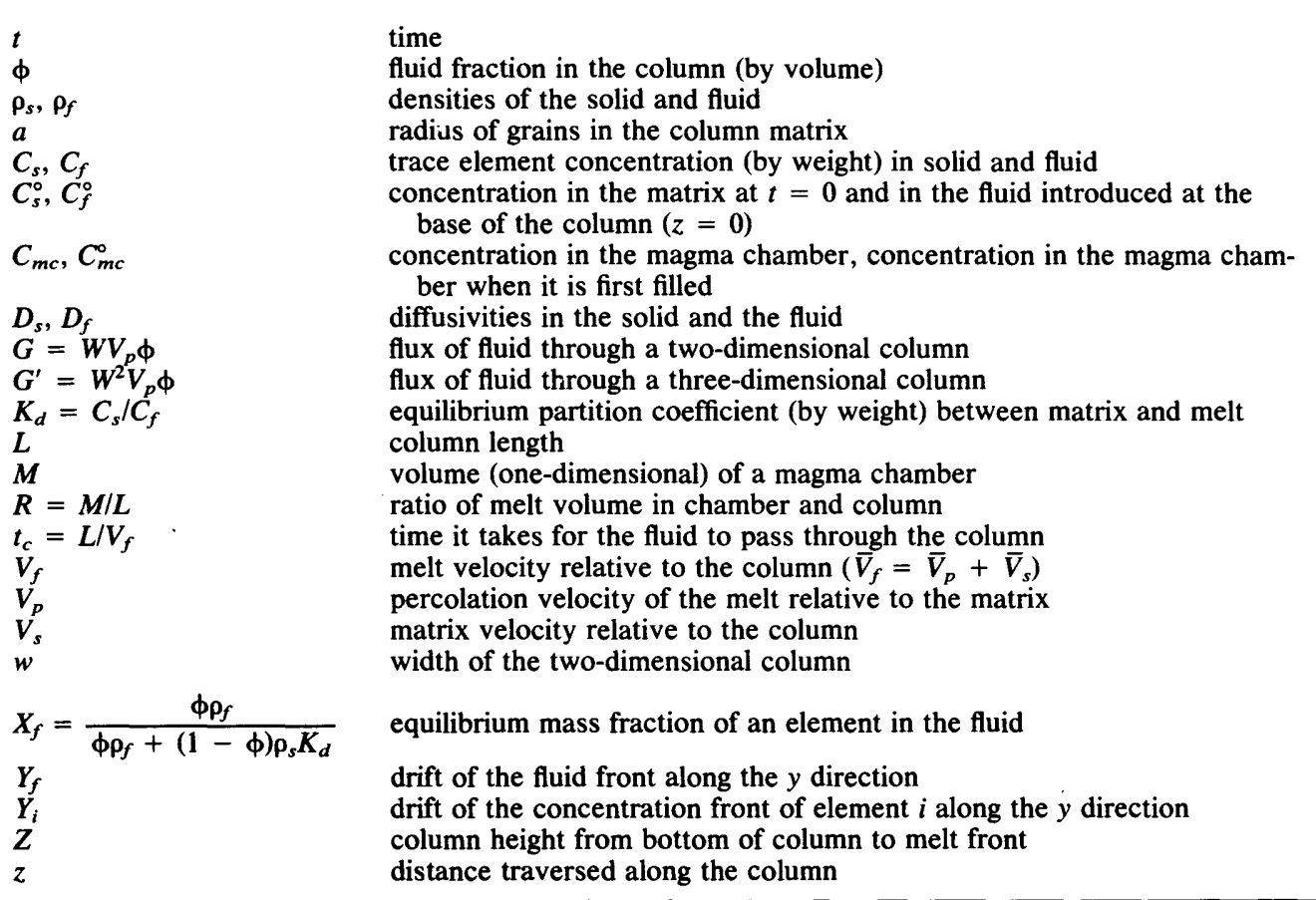

We limit our analysis to the simple cases where densities and diffusivities of solid and fluid, as well as the melt fraction, are constant and uniform. We also assume that the transport of trace elements into and out of the elemental volume by diffusion through the solid phases may be neglected compared with the other fluxes (i.e., $D_{s, i}=0$ ). Omitting the subscript $i$, equation (1) can be rewritten as:

$$
\begin{gathered}
\frac{\partial C_{f}}{\partial t}+\frac{1-\phi}{\phi} \frac{\rho_{s}}{\rho_{f}} \frac{\partial C_{s}}{\partial t}+\bar{V}_{f} \bar{\nabla} C_{f} \\
+\frac{1-\phi}{\phi} \frac{\rho_{s}}{\rho_{f}} \bar{V}_{s} \bar{\nabla} C_{s}-D_{f} \bar{\nabla}^{2} C_{f}=0 .
\end{gathered}
$$

Consider the case of an ideal, one-dimensional column of uniform initial composition in which local equilibrium is established instantaneously and dispersive processes within the fluid are negligible (i.e., $D_{f}=0$ ). The assumption of local equilibrium requires that at any point, $C_{s}=K_{d} C_{f}$, where $K_{d}$ is the partition coefficient for the element of interest. Choosing the matrix as our frame of reference $\left(\bar{V}_{s}=0\right)$, equation (1a) can now be reduced to

$$
\frac{\partial C_{f}}{\partial_{t}}+X_{f} V_{f} \frac{\partial C_{f}}{\partial_{z}}=0
$$

where

$$
X_{f} \equiv \frac{\phi \rho_{f}}{\phi \rho_{f}+(1-\phi) \rho_{s} K_{d}}
$$

$X_{f}$ is the proportion of the trace element in the system that is contained in the fluid at equilibrium.

Equation (1b) describes the rate at which a point of constant concentration moves through the column:

$$
\left(\frac{\partial z}{\partial t}\right)_{C_{f}}=X_{f} V_{f}
$$

Trace element concentrations are transported at lower velocities than the fluid itself. Compatible elements (high $K_{d}$, low $X_{f}$ ) move at a lower rate than more incompatible ones. 
Suppose that a fluid with trace element concentration, $C_{f}^{\circ}$, is introduced continuously into a column with uniform trace element concentration, $C_{s}^{\circ}$. If $C_{s}^{\circ} / C_{f}^{\circ} \neq K_{d}$, the trace element must be exchanged between fluid and matrix, and a sharp concentration front moves through the column at a lower speed than the fluid itself. The fluid ahead of the front is in equilibrium with the original matrix $\left(C_{f}=C_{s}^{\circ} / K_{d}\right)$; behind the front the matrix is in equilibrium with the inflowing fluid $\left(C_{s}=\right.$ $K_{d} C_{f}^{\circ}$.

In the case of this simple boundary condition, the front position is also easily obtainable from a simple mass balance consideration. When the fluid has traveled a distance $Z$ up the column, the trace element content between the base of the column and the height $Z$ must be equal to the initial trace element content of the matrix, $Z(1-\phi) \rho_{s} C_{s}^{\circ}$, plus what was brought in by the fluid, $Z \phi \rho_{f} C_{f}^{\circ}$. Using the equilibrium concentration from the previous paragraph and the fact that the concentration front has traveled a distance $z$, we can express the concentrations in fluid and matrix ahead and behind the front and relate them to the total trace element content of the column between $Z$ and the bottom:

$$
\begin{gathered}
z \phi \rho_{f} C_{f}^{\circ}+z(1-\phi) \rho_{s} K_{d} C_{f}^{\circ} \\
+(Z-z) \phi \rho_{f} C_{s}^{\circ} / K_{d} \\
+(Z-z)(1-\phi) \rho_{s} C_{s}^{\circ}=Z \phi \rho_{f} C_{f}^{\circ} \\
+Z(1-\phi) \rho_{s} C_{s}^{\circ} .
\end{gathered}
$$

The position of the front is then simply

$$
z=X_{f} Z
$$

Figure $1 a$ presents $z / Z$ for some trace elements with different distribution coefficients. Due to their smaller $K_{d}$ values, fronts of incompatible elements move faster than those of more compatible ones. The first fluid emerging from the column is in equilibrium with the initial composition of the matrix, and its trace element concentrations are similar to those produced by incipient melting of the column matrix $\left(C_{f}=C_{s}^{\circ} / K_{d}\right)$. This is true regardless of the fluid fraction in the column or the column length. These two factors determine only the front position and the volume of fluid in front of it. Thus, the chromatographic process is capable of producing ex-



a

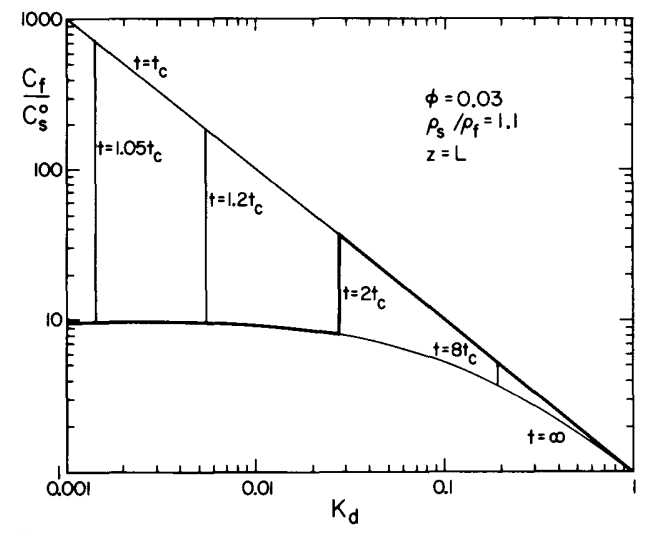

b

FIG. 1.-The ideal column. (a) Fluid concentration of five elements vs. position in the column at $t=t_{c}$, the time when the fluid first reaches the top of the column. Fluid with concentration $C_{f}^{\circ}$ is continuously supplied at the bottom of the column (left end) and flows to the right. As fluid and matrix equilibrate, a sharp front is formed. Ahead of the front the matrix keeps its initial concentration, $C_{s}^{\circ}$, and the concentration in the fluid has changed to $C_{f}$ $=C_{s}^{o} / K_{d}$. Behind it the fluid retains its initial composition and the concentration in the matrix has changed to $C_{s}=K_{d} C_{f}^{\circ}$. Column parameters and the element distribution coefficient are indicated in the figure. Concentrations are normalized to the range spanned by each element. The pattern for $K_{d}=$ 0.011 is enhanced for clarification. (b) Trace element abundance patterns (TEAPs) in fluids emerging from the column at various times. (Concentrations are plotted against $K_{d}$; the REE in a typical peridotite would be distributed more or less evenly between $K_{d} \approx 0.002$ and $K_{d} \approx 0.50$.) In this example, melt introduced at the base of the column is produced by $10 \%$ batch melting of a source similar in composition to the column matrix. The first melt emerging at the top is identical to an infinitesimal partial melt of the column matrix. At later times the fronts of the different elements emerge from the column and their concentrations fall to the lower value of the melt introduced at the bottom. The pattern at $t=2 t_{c}$ is enhanced for clarification. 
treme enrichments of incompatible elements that would otherwise require very small degrees of partial melting. Figure $1 b$ presents the TEAP of melt emerging from a column in which the melt fraction is $3 \%$. Regardless of the original TEAP of the melt introduced at the column base, the melt emerging from the top at $t<1.05 t_{c}\left(t_{c}=L / V_{f}\right.$ is the time it takes for a melt percolating at $V_{f}$ to pass through a column of length $L$ ) has a TEAP characteristic of melt produced by incipient melting of the column matrix (for elements with $K_{d}>$ 0.002 ). Note that in figure $1 b$, concentrations are normalized to the initial matrix composition $C_{f}^{\circ}$, which is not necessarily the same as the initial bulk composition of the column. In particular, if melt fraction $\phi$ is present in the column at $t=0$ due to partial melting of the column matrix, then the matrix is depleted in incompatibles at $t=0$ and the initial matrix concentration $C_{s}^{\circ}$ of incompatible elements will be low relative to more compatible elements. The initial matrix composition $\left(C_{s}^{\circ}\right)$ will only be identical to the bulk composition of the column if the melts penetrate a solid column in which melt fraction $\phi$ is only established during the percolation of melt through the initially dry column.

Melts emerging at later times $\left(t>1.05 t_{c}\right.$ in fig. $1 b$ ) have compatible element concentrations still in equilibrium with the initial matrix composition. The incompatible elements, however, show the characteristics of the melt introduced into the base of the column. Their fronts have traveled the column, and the whole matrix has equilibrated with their initial melt composition. After sufficient volume has passed through it, the column is "used up" even for compatible elements and can no longer affect the melt composition. The column life time for each element is given by $L /$ $\left(V_{f} X_{f}\right)=t_{c} / X_{f}$

\section{SMOOTHING OF THE COLUMN OUTPUT}

Perhaps the most striking feature of the output of the simple column described in the previous section is the abrupt change observed in the trace element pattern as each concentration front reaches the top of the column. The absence of features of this sort in igneous suites of oceanic islands led Hofmann (1984) to conclude that chromatographic processes do not play important roles in their petrogenesis. However, several pro- cesses may lead to the production of smoother patterns in the output of mantlescale columns. In the following sections we examine the potential of external processes acting on the products of the ideal, dispersion-free column, and of internal processes (i.e., those taking place within the column itself) for dispersing the sharp concentration fronts and for smoothing the abrupt TEAPs of the column products.

It should be emphasized that the sharp fronts shown in figure 1 are not just the result of the properties of the ideal column, but also of our choice of initial and boundary conditions. In the case discussed in the previous section, the trace element concentrations in the melt at the base of the column, $C_{f}^{\circ}(t)$ are introduced as a step function at $t=0$. This sudden deviation from equilibrium travels through the column as a series of fronts shaped like step functions (eq. 3). Though these conditions may be appropriate for many situations, in some environments the deviation from equilibrium between melt and matrix may evolve gradually. The initial matrix composition may change along the column length so that the melt is in equilibrium with the matrix at the base of the column and then gradually departs from equilibrium as it travels up the column. The input melt composition may also vary smoothly from equilibrium concentrations to some final $C_{f}^{\circ}(t) \neq C_{s}^{\circ} /$ $K_{d}$. If these changes take place over a time or distance longer than the separation between the fronts of two consecutive elements, smooth and gradually varying TEAPs can be produced in the column output. For example, smooth variations in the melt composition introduced into the base of the column would result if early melts were produced by low degree of partial melting and later ones by progressively higher degrees, or if early melts were produced in a transition zone between the column reservoir and some other reservoir that is the source for later melts.

a. The Perfect Mixer.-One simple way of subduing sharp jumps in TEAPs is through integration and mixing of the column output. If magma is collected someplace (e.g., in a magma chamber below an impermeable layer or in an upper level crustal chamber), the TEAPs in melts coming out of such a chamber are smoothed. Consider the one-dimensional case, in which magma emerging 
a

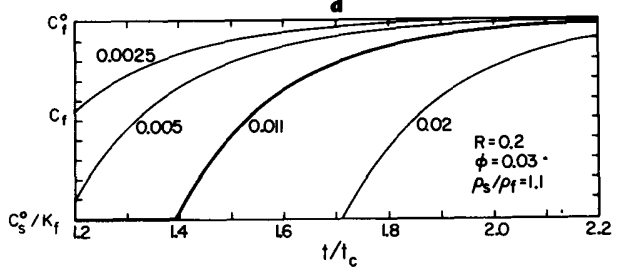

b

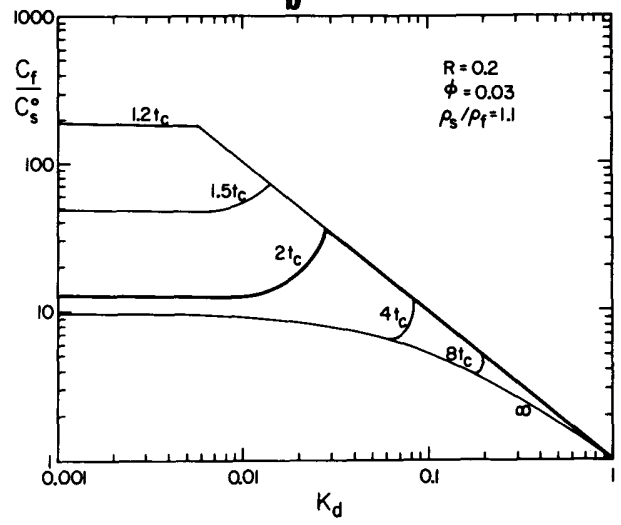

1

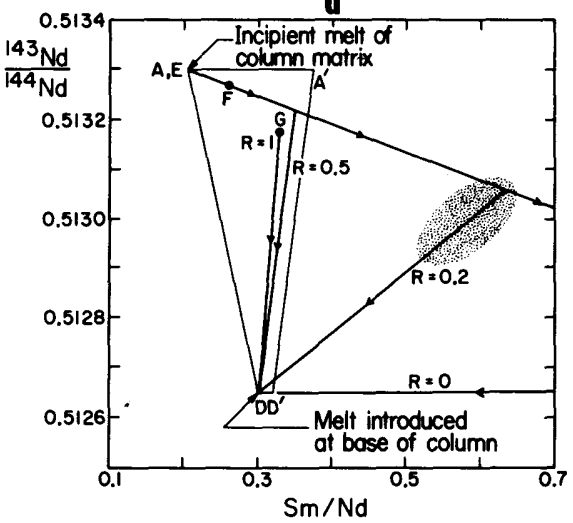

Fig. 2.-Results of collecting and mixing the column output in a magma chamber. The output of the ideal column (fig. 1) is collected and mixed in a magma chamber that is assumed to operate as a perfect mixer. The chamber discharges melt after being filled to a volume of $R L \phi$. (a) Concentrations of four incompatible elements in melts coming out of the chamber $(R=0.2)$ vs. time. Notice the difference from figure $1 a$ where concentrations were plotted against distance. $K_{d}$ values are indicated on the curves. $(b)$ TEAPs of melts emerging from the chamber $(R=0.2)$ at various times. The first melt emerges at $t=(1+R) t_{c}=1.2 t_{c}$, after passing through the column and filling the chamber. Melt and column parameters are identical to those used in figure $1 b$, but the sharp patterns are smoothed relative to the ideal case. (c) The evolution of $\mathrm{La} / \mathrm{Sm}$ vs. $\mathrm{Nd}$. Each solid curve represents the time evolution for a mixer of different volume $(R L \phi) . R=0$ represents the output of an ideai column. The first melt has a composition $A$, which corresponds to the incipient melt of matrix with chondritic concentrations. The more incompatible $\mathrm{La}$ is enriched with respect to $\mathrm{Sm}$. When the La front arrives the ratio changes to $\mathrm{B}$; when the $\mathrm{Nd}$ front arrives, its concentration falls to that of the melt introduced at the base of the column, C. When the Sm front arrives, the Sm concentration falls and $\mathrm{La} / \mathrm{Sm}$ reaches the final value of the melt introduced at the base, D (10\% melt of source with chondritic concentrations). The first composition emerging after being mixed in magma chambers of different sizes is indicated by points A, E, F, G. The evolution curves are smoothed by the effect of the chamber. In all cases, melt composition is clearly distinct from that produced by simple mixing (dashed curve). ( $K_{d}$ values are for a peridotite with $65 \%$ olivine, $20 \%$ orthopyroxene, $10 \%$ clinopyroxene, and $5 \%$ garnet using values from Frey et al. 1978.) (d) Sm-Nd evolution of melt produced by $10 \%$ batch melting of a "bulk earth" reservoir $\left[C_{f}^{\circ}(\mathrm{Nd})=11 \mathrm{ppm}, C_{f}^{\circ}(\mathrm{Sm})=3.3 \mathrm{ppm},{ }^{143} \mathrm{Nd} /{ }^{144} \mathrm{Nd}=0.51265\right]$ percolating through a column of a depleted reservoir $\left[C_{s}^{\circ}(\mathrm{Nd})=0.86 \mathrm{ppm}, C_{s}^{\circ}(\mathrm{Sm})=0.32 \mathrm{ppm},{ }^{143} \mathrm{Nd} /{ }^{144} \mathrm{Nd}=0.51330\right.$; column and mixer parameters and $\mathrm{Sm}$ and $\mathrm{Nd} K_{d}$ values as in fig. $2 c$ ]. Area $\mathrm{A}^{\prime} \mathrm{ADD}^{\prime}$ encloses all possible compositions resulting by simple mixing of $A^{\prime}$, the matrix composition; $A$, its incipient melt; $D^{\prime}$, the source rock; and $D$, its $10 \%$ melt. Note that the composition of the late melts emerging from the magma chamber may be misinterpreted as an isochron or a mixing line of $\mathrm{D}$ or $\mathrm{D}^{\prime}$ with a reservoir represented by the stippled area (for the case of $R=$ 0.2 . The composition of the first melt emerging from chambers with $R=0,0.2,0.5$, and 1 are represented respectively by points $A, E, F$, and $G$. 
from a column of length $L$ and porosity $\phi$ is collected and mixed in a region above the column. The newly formed magma chamber grows to a thickness $M$, and then discharges magma at the same rate as it is recharged. If mixing in the chamber is perfect (i.e., occurs instantaneously), then conservation of mass for any trace element requires:

$$
M \frac{d C_{m c}}{d t}=\phi V_{f}\left(C_{f}-C_{m c}\right)
$$

where $C_{f}$ is the trace element concentration in the melt entering the chamber and $C_{m c}$ is the concentration of the trace element in the chamber. In the case of a chamber above an ideal column, $C_{f}=C_{s}^{\circ} / K_{d}$ until the front enters the chamber at $t=t_{c} / X_{f} \lambda(t=0$ refers to when the melt is first introduced at the bottom of the column). At later times, $C_{f}=C_{f}^{\circ}$.

For any given size of magma chamber there is a critical value of $K_{d}$ for which the volume of melt ahead of the concentration front is equal to the chamber volume:

$$
M=L \phi\left(\frac{1}{X_{f}}-1\right)
$$

More compatible elements have a larger volume ahead of their fronts, and the trace element concentration in the chamber when it is first filled is $C_{m c}^{\circ}=C_{s}^{\circ} / K_{d}$. For more incompatible elements the volume of melt ahead of the front is smaller, and $C_{m c}^{\circ}$ is given by:

$$
\frac{C_{m c}^{\circ}-C_{f}^{\circ}}{C_{s}^{\circ} / K_{d}-C_{f}^{\circ}}=\frac{1}{R}\left(\frac{1}{X_{f}}-1\right)
$$

where $R=M / L \phi$ is the ratio of melt volume in the chamber to that in the column.

In the case of a chamber above an ideal column the solution of equation (6) is a simple exponential decay to the final concentration, $C_{f}^{\circ}$. In the case of the compatible elements the decay starts when the front reaches the chamber, $t=t_{c} / X_{f}$; in the case of the incompatibles the decay starts at the time the chamber is first filled, $t=t_{c}(1+R)$. In both cases the time constant for decay is $M / V_{f} \phi=R t_{c}$.

Figure $2 a$ presents the results for a reservoir with $R=0.2$ placed above the ideal column of figure 1 . The sharp fronts of the ideal case are relaxed into exponential decay with time. If the concentration fronts of "consecu- tive" elements (e.g., La, Ce) overlap (fig. $2 a$ ), the sharp jumps produced by the ideal column are smoothed (fig. $2 b$ ). This effect is more pronounced for incompatible elements than for compatible elements.

Inspection of figures $1 b$ and $2 b$ shows that concentration ratios of incompatible to compatible elements can undergo extreme variations in successive melts emerging from an ideal column or from a magma chamber above such a column. These changes are illustrated in figure $2 c$. For the ideal column, the initial output has a ratio of $\left(C_{s, \mathrm{La}}^{\circ} / K_{d, \mathrm{La}}\right) /$ $\left(C_{s, \mathrm{Sm}}^{\circ} / K_{d, \mathrm{Sm}}\right)$ (point A). The ratio then jumps to $C_{f, \mathrm{La}}^{\circ} /\left(C_{s, \mathrm{Sm}}^{\circ} / K_{d, \mathrm{Sm}}\right) \quad(\mathrm{B}, \mathrm{C})$ and finally changes to $C_{f, \mathrm{La}}^{\circ} / C_{f, \mathrm{Sm}}^{\circ}(\mathrm{D})$. This path of evolution of melt composition is clearly distinct from that produced by simple mixing of the incipient melt of the column matrix with the melt introduced at the base (dashed line). Note that for small magma chambers the chromatographic process is capable of producing element ratios that cannot be explained by simple mixing of any two melts plotting at $\mathrm{A}$ and $\mathrm{D}$; i.e., $\mathrm{La} / \mathrm{Sm}$ ratios lower than that of point $\mathrm{D}$ can be produced.

Isotopes of the same element are equally affected by the column and evolve similarly because they have the same value of $K_{d}$. The change in isotopic ratio is the same as during simple mixing. Thus, if ${ }^{143} \mathrm{Nd} /{ }^{144} \mathrm{Nd}$ were plotted versus $1 / \mathrm{Nd}$, a straight line would result, similar to a mixing line between incipient melt of the matrix and melt input into the base of the column. However, since ratios of elements of different compatibilities can vary widely in the output of a single column (fig. $2 c$ ), parent-daughter evolution diagrams can display some unusual trends. In figure $2 d$, we have constructed a $\mathrm{Sm} / \mathrm{Nd}$ evolution diagram for an ideal column and various magma chamber sizes for specific choices of $K_{d}, C_{f}^{\circ}$, $C_{s}^{\circ}$ and ${ }^{143} \mathrm{Nd} /{ }^{144} \mathrm{Nd}$ ratios for the matrix and the melt introduced at the column's base. For the ideal case $(R=0)$, the abrupt variations in $\mathrm{Sm} / \mathrm{Nd}$ ratios as the two fronts arrive, coupled with the jump in the $\mathrm{Nd}$ isotopic ratio when the $\mathrm{Nd}$ front arrives, produce an extreme pattern. For the magma chamber cases, trends that resemble isochrons or mixing lines are produced. These clearly have no time significance, nor do they necessarily yield any direct information on the properties of the two components (i.e., percolating melt 
and matrix) being "mixed" in the chromatographic column. For example, melts along the $R=0.2$ trend in figure $2 d$ could be misinterpreted as mixing between $\mathrm{D}$ or $\mathrm{D}^{\prime}$ and a recently depleted reservoir (stippled area). Similar results are produced on a $\mathrm{Rb} / \mathrm{Sr}$ evolution diagram. On an $\epsilon_{\mathrm{Nd}}-\epsilon_{\mathrm{Sr}}$ plot (DePaolo and Wasserburg 1976), the interaction between melts and matrix lying along the manthe array may deviate from the array, because $\mathrm{Sr}$ is more incompatible than $\mathrm{Nd}$ and $\epsilon_{\mathrm{Sr}}$ would change faster than $\epsilon_{\mathrm{Nd}}$.

The ion-exchange process, softened to some extent by a "perfect mixer," can thus produce smoothly varying trace element patterns. If elements covering a wide range of compatibilities are studied, the output of this process should be distinguishable from other fractionation processes; it could be misinterpreted if only isolated parts of the data set were examined.

b. Internal Dispersive Processes.-In a realistic column, dispersive processes within the column itself could lead to diffuse fronts and smooth TEAPs in the column output. For example, chemical diffusion must occur across the concentration fronts, with the result being more dispersed, wider fronts. Mechanical dispersion, which is the result of processes such as capillarity in the tubules or the column tortuosity, mixes fluid parcels across the front and has a similar effect. Slow volume diffusion in the solid matrix may prevent local equilibrium between fluid and solid during flow and lead to dispersion of sharp concentration fronts.

Whereas an "ideal" column can be fully characterized by the melt fraction and partition coefficients, examination of dispersive processes requires knowledge of some other parameters: grain size, flow velocity, diffusivities in the fluid and the solid, and fluid viscosity. Current knowledge of most of these parameters is sufficient for us to assess the likely contributions of the various dispersive processes.

(i) Chemical diffusion in the fluid. Chemical diffusion must occur across the concentration fronts in the column, resulting in dispersed, wider fronts. In order to evaluate the magnitude of this effect, we reduce equation (1a) to the following form for a onedimensional column, everywhere in local equilibrium, in which the matrix is chosen as the reference frame:

$$
\frac{\partial C_{f}}{\partial t}+X_{f} V_{f} \frac{\partial C_{f}}{\partial z}-X_{f} D_{f} \frac{\partial^{2} C_{f}}{\partial z^{2}}=0
$$

Consider, as we did earlier, the case where melt with constant trace element concentration $C_{f}^{\circ}$ is continuously introduced at the bottom of a column of uniform composition. For these initial conditions equation (9) can be solved by the Laplace Transform, and for the case of $C_{f}^{\circ} \neq C_{s}^{\circ} / K_{d}$ :

$$
\begin{gathered}
\frac{C_{f}-C_{f}^{\circ}}{C_{s}^{o} / K_{d}-C_{f}^{\circ}}=\frac{1}{2}\left\{\operatorname{erfc}\left[\left(\frac{V_{f}}{4 D_{f}}\right)^{1 / 2} \frac{z-z_{\text {front }}}{\left(z_{\text {front }}\right)^{1 / 2}}\right]\right. \\
\left.+\exp \left[\frac{z V_{f}}{D_{f}}\right] \operatorname{erfc}\left[\left(\frac{V_{f}}{4 D_{f}}\right)^{1 / 2} \frac{z+z_{\text {front }}}{\left(z_{\text {front }}\right)^{1 / 2}}\right]\right\} .
\end{gathered}
$$

The physical situation described by equations (9) and (10) is that of a concentration front that moves through the column with a velocity $V_{f} X_{f}$. The front, centered at $z=z_{\text {front }}$ $=X_{f} V_{f} t$, is dispersed and is in the form of an error function. (A related case of a spike in the fluid concentration is discussed by McKenzie 1984.) The last term in equation (10), which takes care of the initial condition at $z=0$, can be neglected for $z_{\text {front }}>4 D_{f} / V_{f}$.

The extent to which chemical diffusion can smooth TEAPs (i.e., subdue the sharp steps shown in fig. 1b) may be evaluated by comparing the width of the dispersed front to the separation between the fronts of two trace elements, $i$ and $j$. The width of the dispersed front at the time it emerges from the column may be obtained as:

$$
\begin{aligned}
\Delta^{\text {diff }} & =2\left(z_{*}-z_{\text {front }}\right) \\
& =4\left(\frac{D_{f} z_{\text {front }}}{V_{f}}\right)^{1 / 2}=4\left(\frac{D_{f} L}{V_{f}}\right)^{1 / 2}
\end{aligned}
$$

where $z_{*}$ is that for which the argument in the erfc function is 1 . When the front of $i$ reaches the top of the column, the front of $j$ is at $L X_{f, j} /$ $X_{f, i}$. The separation between the fronts is:

$$
\Delta^{\text {sep }}=L\left(1-\frac{X_{f, j}}{X_{f, i}}\right)
$$


and

$$
\frac{\Delta^{\mathrm{diff}}}{\Delta^{\mathrm{sep}}}=\frac{4 X_{f, i}}{X_{f, i}-X_{f, j}}\left(\frac{D_{f}}{V_{f} L}\right)^{1 / 2}
$$

Dispersion of the concentration fronts is effective at smoothing trace element patterns if this ratio is greater than one. For the case of the fronts of $\mathrm{Nd}$ and $\mathrm{Sm}$ in basaltic melt percolating through peridotite, we obtain $X_{f, \mathrm{Nd}}$ $=0.72, X_{f, \mathrm{Sm}}=0.58$ (using the parameters of fig. $2 c) . D_{f}$ is of the order of $10^{-6}-10^{-7} \mathrm{~cm}^{2} /$ sec (Magaritz and Hofmann 1978), so that even for low percolation velocity $(1 \mathrm{~cm} / \mathrm{yr})$, diffusion is important only in columns shorter than $70 \mathrm{~m}$.

We conclude, therefore, that chemical diffusion in the fluid is inefficient at dispersing the sharp fronts of the ideal column. It may be of importance in the cases of very incompatible elements (fronts are not well separated), short columns ( $L<1 \mathrm{~km})$, and low percolation velocities.

(ii) Mechanical dispersion. Mechanical dispersion may also contribute to the broadening of the concentration fronts in mantle columns. Mechanical dispersion (also called hydrodynamic dispersion; Bear 1972; Dullien 1979) is the result of processes that lead to mechanical mixing of the fluid. For example, during flow in a single tubule, capillarity and the irregular shape of the tube result in the dispersion of the front due to mechanical stirring of the fluid across the front. Fluid from the two sides of the front may also be mixed due to the different random paths of fluid parcels through the network of tubules.

It is possible to estimate the extent to which mechanical dispersion can broaden concentration fronts. Under some simplifying assumptions (Bear 1972; Dullien 1979), the effects of mechanical dispersion can be accounted for by replacing $D_{f}$ in equation (9) by total dispersivity, $D_{f}^{\prime}$, which includes contributions from both chemical diffusion and mechanical dispersion. $D_{f}^{\prime}$ can be described as a function of the medium Peclet number, $P e^{\prime}=$ $a V_{f} / D_{f}$, which is the ratio of the time it takes to travel a characteristic distance $(a)$ by diffusion, $a^{2} / D_{f}$, and by advection, $a / V_{f}$.

If $P e^{\prime}<1$, then mechanical dispersion is less efficient than chemical diffusion and $D_{f}^{\prime}$ $\sim D_{f}$ (Dullien 1979). For $P e^{\prime}>1, D_{f}^{\prime}$ can be approximated by

$$
D_{f}^{\prime}=a V_{f}
$$

(Dullien 1979). For a typical column with $D_{f}$ $=10^{-6}-10^{-7} \mathrm{~cm}^{2} / \mathrm{sec}, V_{f}=0.1-100 \mathrm{~cm} / \mathrm{yr}$, $a=0.1-1 \mathrm{~cm}, P e^{\prime}$ is between $10^{-3}$ and 100 . Equation (13) describes the situation for $P \boldsymbol{e}^{\prime}$ $<1$. For $P e^{\prime}>1$, we substitute $D_{f}^{\prime}=a V_{f}$ for $D_{f}$ in equation (13) yielding:

$$
\frac{\Delta^{\mathrm{disp}}}{\Delta^{\mathrm{sep}}}=\frac{4 X_{f, i}}{X_{f, i}-X_{f, j}}\left(\frac{a}{L}\right)^{1 / 2} .
$$

Using $X_{f, \mathrm{Nd}}=0.72, X_{f, \mathrm{Sm}}=0.72$ as in the previous section yields $\Delta^{\text {disp }} / \Delta^{\text {sep }}>1$ only for $L<4 \mathrm{~m}$. This estimate may be modified somewhat due to the effects of varying packing of grains or irregular grain geometry on dispersivity. Limited measurements and calculations suggest that increase in $D_{f}^{\prime}$ of two orders of magnitude is possible (Dullien 1979). However, even such enhanced dispersivities would not result in broadening of concentration fronts comparable to the separation between them for $\mathrm{km}$-scale columns.

(iii) The effect of diffusion in the solid phases. Up to this point, we have simplified our analysis with the assumption of instantaneous, local equilibrium between melt and solid matrix in the column; i.e., at all points, $C_{s}=C_{f} K_{d}$. However, it is easy to see that this assumption will be unjustified if grain size in the matrix is large enough (or meltsolid contact is limited by the restriction of melt to tubules in partially molten systems; F. Richter, pers. comm.) or melt velocity is high enough. Suppose, for example, that the column's grain size is $1 \mathrm{~cm}$ and the diffusivity in the solid is about $10^{-13} \mathrm{~cm}^{2} / \mathrm{sec}$ (e.g., rare or alkaline-earth elements in diopside and garnet at $1200^{\circ} \mathrm{C}$; Freer 1981 ; Sneeringer et al. 1984). The time scale for equilibration would be on the order of 300,000 yrs. This may be comparable to the lifetime of a Hawaiian volcano (Shaw et al. 1980) and to the time required for basaltic melt to traverse a 10-km column of $1 \mathrm{~cm}$ grain size (McKenzie 1985; Scott and Stevenson 1986). The effects of slow volume diffusion in the matrix may thus be important for the kind of processes we are considering and, as we shall show, are likely to be the most important sources of dispersion. 
Without the assumption of instantaneous local equilibrium, analytical solution of equation (1a) becomes difficult; $C_{f}$ and $C_{s}$ must now be related through a diffusion law rather than through the simple expression $C_{s}=$ $C_{f} K_{d}$. We have constructed a numerical solution to equation (1a) using Fick's second diffusion law to describe the diffusion through a stationary matrix consisting of spherical grains. Diffusion and mechanical dispersion in the fluid were shown earlier to be small and have been neglected. The details of the numerical solution are described in Appen$\operatorname{dix}$ A.

Figure $3 a$ presents concentration fronts for
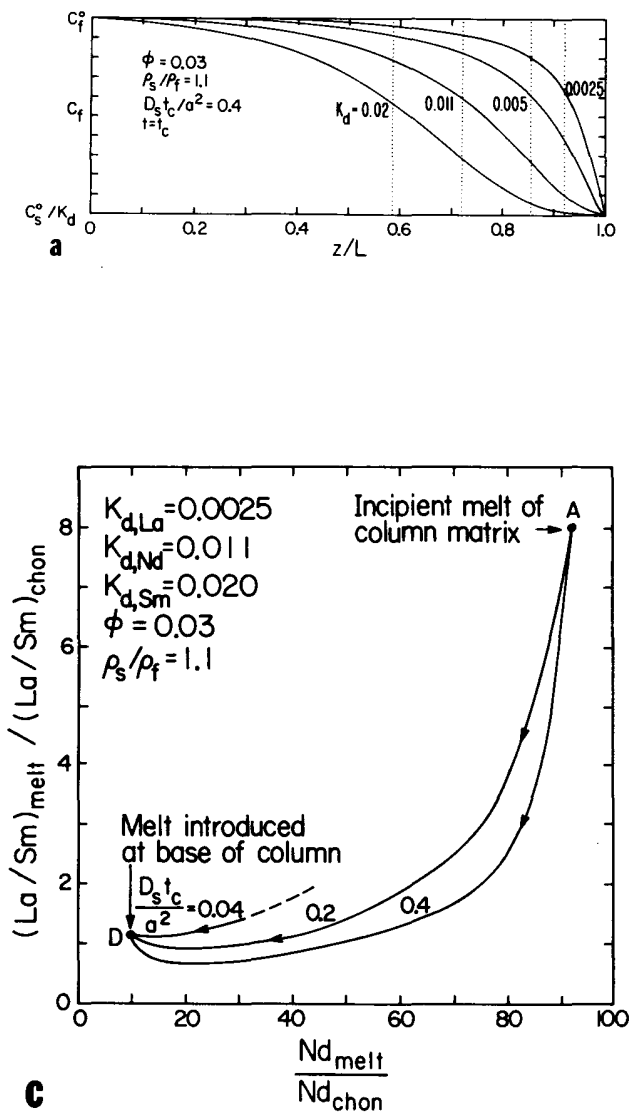

a sample calculation when the melt has just reached the top of the column $\left(t=t_{c}\right)$. It is clear that the slow diffusion in the solid does lead to a strong dispersion of the fronts and to a substantial overlap between fronts of different elements. Another factor contributing to the good overlap is the faster rate at which the fronts move compared with the equilibrium case (dotted lines). This faster rate of front migration results from the weaker interaction between fluid and solid. In the extreme case, when no equilibration takes place, the concentration fronts of all elements travel at the fluid velocity.

The overlap shown in figure $3 a$ results in
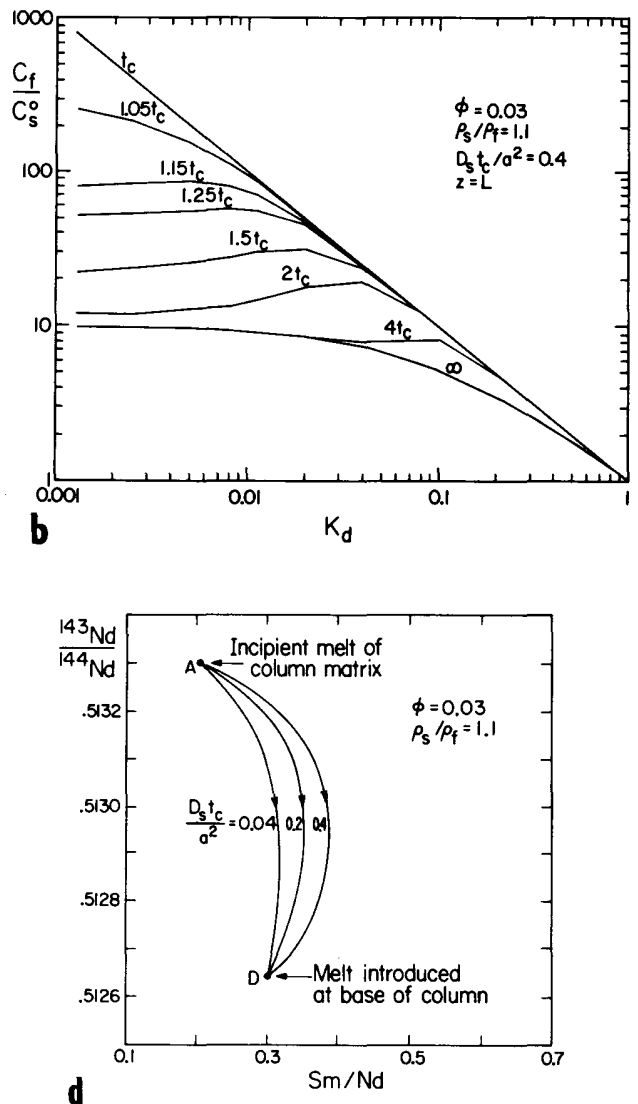

Fig. 3.-Incomplete equilibration due to slow volume diffusion in the solid. (a) Trace element concentrations vs. position within the column at $t=t_{c}$. Notice that fronts advance a larger distance than in the equilibrium case (dotted lines) and that elements of different compatibility have fronts of different width. (Column parameters and $K_{d}$ values are indicated in the figure. $D_{s} t_{c} / a^{2}$ is the ratio of advective and diffusive time scales, which controls the column's approach to local equilibrium.) (b) TEAPs in fluid emerging at $L$ at various times. (c) The evolution of $\mathrm{La} / \mathrm{Sm}$ vs. Nd. Each curve represents the time evolution for a different value of $D_{s} t_{c} / a^{2}$. Composition of matrix and melt introduced into the column as in figure $2 c$. (d) Sm-Nd evolution diagram. Melt and column parameters as in figure $2 d$. 
smooth TEAPs (fig. $3 b$ ) that change gradually with time. The characteristic features of the chromatographic column, mainly the evolution from incipient melt of the column matrix to the composition of the melt introduced into the column's base and the faster evolution of the incompatible elements, are still present.

Figures $3 c$ and $3 d$ show variations in incompatible to compatible element ratios and a representative parent-daughter isotope evolution diagram. Again, though the trends are smoothed, they preserve the characteristic features of the chromatographic process (compare with figs. $2 c$ and $2 d$ ).

The shape of each front can be approximated by an error function solution similar to equation (10) where $D_{f}$ is replaced by

$$
" D "=\frac{a^{2} V_{f}^{2}}{4 \pi D_{s}} X_{f}\left(1-X_{f}\right)
$$

(see Appendix A). The ability of slow diffusion in the solid to produce overlap between fronts of different elements may be examined by substituting " $D$ " into equation (13):

$$
\frac{\Delta^{\mathrm{diff}}}{\Delta^{\mathrm{sep}}}=\frac{4 X_{f, i}}{X_{f, i}-X_{f, j}}\left[\frac{a^{2} V_{f}}{D_{s} L} \frac{X_{f, i}\left(1-X_{f, i}\right)}{4 \pi}\right]^{1 / 2} .
$$

Recall that dispersion of the concentration fronts leads to smoothing of the trace element patterns if this ratio is greater than one. In the case of basaltic melt flowing through matrix with $a=0.5 \mathrm{~cm}$ at a velocity $V_{f}=30 \mathrm{~cm} / \mathrm{yr}$, we obtain for $\mathrm{Nd}\left(K_{d}=0.011\right)$ and $\operatorname{Sm}\left(K_{d}=\right.$ $0.02), \Delta^{\text {diff }} / \Delta^{\text {sep }}>1$ for $L<170 \mathrm{~km}$ (using column parameters of figures 2 and 3 with $D_{s}$ $=10^{-13} \mathrm{~cm}^{2} / \mathrm{sec}$; Sneeringer et al. 1984). Under these conditions $\Delta^{\mathrm{diff}} / \Delta^{\text {sep }}>1$ for $L<$ $404 \mathrm{~km}$ in the case of the incompatible elements $\mathrm{La}\left(K_{d}=0.0025\right)$ and $\mathrm{Ce}\left(K_{d}=0.05\right)$. For the more compatible elements $\mathrm{Yb}\left(K_{d}=\right.$ $0.23)$ and $\mathrm{Lu}\left(K_{d}=0.38\right), \Delta^{\text {diff }} / \Delta^{\text {sep }}>1$ in columns shorter than $23 \mathrm{~km}$. Thus, in $\mathrm{km}$ scale columns, slow diffusion in the solid matrix is found to be efficient in dispersing the fronts and smoothing the sharp TEAPs predicted for the ideal case.

It is important to emphasize the strong dependence of equation (16) upon grain size. Since $V_{f} \propto a^{2}$ during permeable flow (Bear 1972), the parameter $a^{2} V_{f} / D_{s} L$ goes as $a^{4}$.
Thus, for example, if $a=0.1 \mathrm{~cm}, \Delta^{\text {diff }} / \Delta^{\text {sep }}>$ 1 only if $L<270 \mathrm{~m}$ (for $\mathrm{Nd}$ and $\mathrm{Sm}$ ). For matrix with this grain size, the assumption of local equilibrium would be appropriate if columns are more than a few kilometers long (McKenzie 1984; Richter 1986), and smooth TEAPs would not characterize the output of such columns. If grain size is larger than a few centimeters, or if flow is in veins so that the effective "grain size" is even larger, diffusive interaction would probably be small, and melts would be little influenced by the wallrock; however, any interaction that occurred under these conditions could still be described by the treatment we have developed.

If solid and melt react so that solid phases dissolve and/or crystallize, or if recrystallization is important, then trace element transfer across the solid-melt interface would be enhanced. It was suggested by Norton and Taylor (1979) that the same mathematical scheme we have used is applicable in this case if diffusivity is replaced by transfer rate coefficients. Although very little is known of the kinetics of trace element transfer in such systems, it seems plausible that under such conditions columns could operate close to equilibrium whether melt flows along grain boundaries or in small veins.

\section{DISCUSSION}

The essence of the kind of process we envision and have described in the previous sections is as follows: melt is continuously introduced at the base of a column of rock and moves upward through it by permeable flow. The melt is initially out of equilibrium with the rock matrix, and the two interact chemically. A snapshot of the column at any time would show for each element a concentration front, above which the melt is in equilibrium with the initial matrix of the column and below which the melt is unchanged from when it was introduced into the base of the column. Above the concentration front, the matrix retains the initial column composition; below it, the matrix has changed to be in equilibrium with the melt flowing into the column. The width of the front depends on the effectiveness of dispersive processes in the column.

If we looked at a movie of the column, we 
would see the concentration front for each element sweeping upward, with the fronts of the more incompatible elements moving faster than those of the more compatible ones. If we sat on the top of the column and sampled the liquids that emerged, we would first collect melt identical to that of an infinitesimal degree of partial melting of the initial matrix material. As the concentration front of each element reached the top of the column (the fronts would arrive in order of increasing compatibility), we would observe the melts changing from the concentration of that element in the incipient melt of the matrix to that of the melt flowing into the column's base. Eventually, the concentration fronts of even the most compatible elements will have reached our position, and thereafter, the melts that emerge will be identical to those injected into the base of the column.

The features that should be emphasized are the rapid evolution of the incompatible elements relative to the compatible elements in the melts emerging from the column, the extreme fractionations possible via the operation of such a column, and its transient nature. These will be preserved in all incarnations of this process.

Chromatographic columns are well known for the strong chemical separations they produce. Sharp fronts are produced if local equilibrium is instantaneously established between melt and matrix, and dispersive processes are not efficient enough to broaden them. We have evaluated the dispersive effects of some internal processes such as chemical diffusion in the liquid, physical mixing across the concentration front, and incomplete local equilibrium between melt and matrix due to slow diffusion in the solid phases. We conclude that incomplete local equilibration due to slow diffusion in the solid phases is likely to be the most important and effective agent of dispersion in columns where basaltic melts percolate through mantle rocks. Chemical diffusion in the melt will play a role only if melt velocity is low or columns are shorter than a kilometer. Mechanical dispersion is not likely to be important when melt percolates along grain boundaries.

Broad fronts and smooth trace element abundance patterns may also be produced by other processes. Matrix composition, and hence the distribution coefficients between melt and matrix, may change along the column length, or input melt composition may change gradually with time, so that the deviation from equilibrium between the column and the percolating melt evolves gradually. Integrating and mixing the column products in a magma chamber can also be effective in softening the sharp fronts produced by a mantle column.

It is instructive to compare the outputs of a hypothetical mantle column and of simple mixing of the melt introduced into the base of the column with the incipient melt of the column's matrix. After all, both processes produce a continuum of melt compositions ranging between that of the incipient melt and the melt flowing into the column. The intermediate products of the two processes are, however, quite distinguishable (e.g., fig. 2c). Basically, in the ion-exchange process, each element can be regarded as mixing at a different rate, which is a function of the element's compatibility with respect to the matrix, with incompatible elements changing rapidly between the two end members and the compatible elements doing so slowly. Thus, although the end members of the two processes are the same, by examining the variations in a range of compatibles versus incompatibles in the intermediate members of a series of magmas, they should be readily distinguishable.

The chromatographic process has important similarities to zone refining (Harris 1957). If the volume of the refined zone is infinitesimally small and the process is repeated continuously, the results are identical to those of our equilibrium case. However, while in the case of zone refining, melt-matrix interaction is achieved by melting of the matrix and subsequent crystallization from the melt, our treatment has focused on diffusive interaction between the two media.

Caveats.-In order to bring out the main features of the chromatographic process, we have focused upon a highly schematic model of mantle processes. At this point, it is worth evaluating the degree to which actual mantle processes and conditions may deviate from these we have modeled. It seems inevitable that fluids (melts or volatile-rich supercritical fluids) will pass through country rocks with which they are not in equilibrium as they rise buoyantly. The lack of equilibrium may be the result of disequilibrium melting, migra- 
tion of melts through a phase boundary (i.e., the garnet to spinel peridotite transition), or migration of melt between regions that have undergone different degrees of partial melting or between reservoirs of different chemical composition. It is less certain, however, that the melts are always able to interact chemically with country rocks as they traverse them. Flow of melt through narrow cracks may result in extensive interaction (Quick 1981) and melt percolation along grain boundaries, the flow process considered by us in our modeling of ion-exchange processes, will clearly allow the necessary interaction. On the other hand, crack propagation or diapiric rise are so rapid and the surface area to volume ratios so low that chemical interactions for these modes of magma transport are likely to be minimal, though the effects of whatever interactions do occur may be similar to those we have described.

In order to process melt quantities that are important on a regional scale, columns must be on the order of $1 \mathrm{~km}$ or longer. At present, it is not known whether narrow (cm-scale) veins or porous flow are stable over such distances relative to the development of larger dikes and conduits, in which chemical interaction of melts with wallrock is minimal. Also, the onset of permeability in a previously dry rock, though experimentally observed (Watson 1982), is not yet physically understood.

Perhaps the most important limitation of our modeling, and indeed of thinking about the process that we have envisioned in any geologically realistic situation, is that the only interaction between melt and matrix that we consider is ion-exchange. This implies the stringent limitation that, with respect to mineralogy (i.e., major elements), the fluid and the matrix are already in equilibrium when the fluid is introduced into the base of the column. If they are not, dissolution and precipitation of matrix phases or perhaps even new phases will occur.

The end member process we have described will be most relevant to scenarios in which fluids pass between regions of the mantle that have similar mineralogies (the same phases with similar major element chemistries, but not necessarily in the same proportions) but different minor and trace element characteristics. Since heat and most major elements will behave as "compatible elements," minor incompatibilities between the phase equilibria of the injected fluid and the mineralogy of the matrix will probably be adjusted by reactions occurring at the base of the column, and the end member ionexchange process may then be relevant to the movement of the melt through the bulk of the column.

Other complexities may arise because of the pressure and temperature gradients along the column. These may lead to non-uniform composition of the initial column and to changes in the phase equilibria controlling the melt-matrix reactions. The non-uniformity of the initial column could be easily modeled by allowing for variability of the distribution coefficients with height. The effect of the pressure and temperature gradients on meltmatrix reactions is more difficult to estimate, given the paucity of relevant phase equilibrium data, and would also require specification of the pressures and temperatures throughout the column and in the melt flowing into it. Characterization of these aspects of the interaction of melt and matrix is beyond the scope of this paper, but we note that the ion-exchange process upon which we have focused will be superimposed on these phase equilibrium effects.

Geological Applications.-Up to this point, we have purposely kept the modeling and discussion rather abstract so as to emphasize the general features of the ionexchange process and the effects of varying the parameters in the models. There are many possible situations involving different matrices, column geometries, initial melt compositions, and plumbing systems that could be modeled in detail. Rather than trying to anticipate all potential applications, we will briefly develop three geologically interesting scenarios in which ion-exchange processes might be important. Through these, we hope to demonstrate the kinds of observable geochemical features of natural suites that might reflect the involvement of $\mathrm{km}$ scale chromatographic columns in mantle rocks.

a. Mantle metasomatism: U-shaped REE patterns in peridotites. Our discussion has focused on the characteristics of the liquids that emerge from hypothetical mantle-scale chromatographic columns, but the com- 
plementary evolution of the matrix composition is also of interest and may provide insights into the observed compositions of mantle-derived ultramafic xenoliths and terrains. The model that we have developed provides a framework for considering the effects of mantle metasomatism as fluids (silicate or carbonatite melts or hydrous or $\mathrm{CO}_{2}$-rich supercritical fluids) flow through mantle rocks and alter their composition.

An example of such a process is presented in figure 4. A column, initially depleted in light REE, is penetrated by a melt highly enriched in these elements. As $C_{f}^{\circ}>C_{s}^{\circ} / K_{d}$, rare earth elements are transferred from the melt to the matrix. After small quantities of melt pass through the column, the fronts of the more incompatible, light REE reach the top of the column, their concentrations rise, and the matrix in this region develops U-shaped REE patterns. Later, other fronts arrive and the point of the minimum concentration moves toward the more compatible elements. After enough fluid has passed through the column, the pattern relaxes to the final equilibrium shape.

This scenario is a possible explanation for U-shaped REE patterns observed in some metasomatized peridotitic nodules (Stosch and Seck 1980; Dupuy et al. 1986) and peridotites from some ophiolitic bodies (Pallister and Knight 1981; Prinzhofer and Allegre 1985). Such peridotites could have evolved initially as residues from extensive partial melting of a typical source rock for midocean ridge basalts, or as cumulates from such magmas, and developed light REE depleted patterns [similar to the patterns observed in some Kilbourne Hole nodules (Irving 1980) or in the Ronda peridotite (Frey et al. 1985)]. A later interaction of these rocks with a limited volume of light REE enriched fluid or melt could lead, according to the above scenario, to the formation of $U$-shaped REE patterns.

Simple mixing of an enriched component and depleted matrix could also lead to Ushaped REE patterns, but given an appropriate data set, the two processes could be distinguished. Such a data set is illustrated in figure 5, where we have plotted the REE concentrations of a suite of nodules with Ushaped REE patterns from Hoggar, Algeria (Dupuy et al. 1986). The patterns are clearly

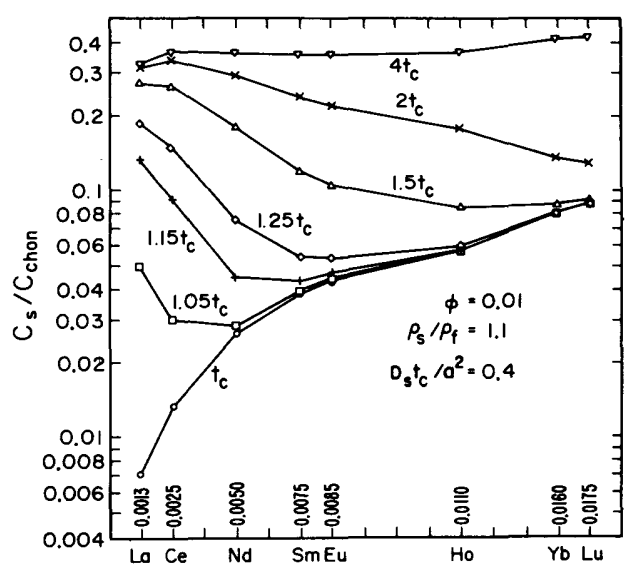

Fig. 4.-Evolution of REE abundance patterns during metasomatism of a depleted mantle infiltrated by a melt highly enriched in incompatible elements. The matrix at the top of the column retains its initial composition until the first melt reaches it at $t=t_{c}$. Then, since fronts of the more incompatible elements travel faster through the column, their concentrations rise earlier and a Ushaped trace element pattern evolves. If melt volume is limited $(0.05 L \phi-0.15 L \phi$ in the case shown), then interaction ends at $t=1.05 t_{c}-1.15 t_{c}$ ) and these U-shaped patterns are the final ones. If more melt is available, then matrix composition will continue to evolve toward equilibrium $\left(t=1.25-4 t_{c}\right)$. Melt composition is that produced by $0.1 \%$ batch melting of a source with chondritic abundance and with $65 \%$ olivine (ol) + spinel (sp), $22 \%$ orthopyroxene (opx), and $13 \%$ clinopyroxene (cpx). Matrix composition is that of a residue after a $\mathbf{2 0 \%}$ batch melting of a similar source, and is composed of $74 \% \mathrm{ol}, 22 \%$ opx and $4 \% \mathrm{cpx} . K_{d}$ values for the column were calculated using the values given by Frey et al. (1978) and are indicated in the figgure.

distinguishable from the linear arrays expected in the case of simple mixing. They are, however, very similar to what we would expect if a chromatographic process produced the range of observed REE patterns. The concentration fronts of the more incompatible elements move faster through the chromatographic column and their concentrations rise first. Figure 5 shows that, in accordance with the predictions of our model, the $\mathrm{Ce}$ and Nd concentrations in the nodules increase faster than does the concentration of the more compatible $\mathrm{Sm}$, resulting in concave downward arrays. The Eu and Sm concentrations rise at comparable rates, as expected for two elements with similar $K_{d}$ values. Yb and $\mathrm{Lu}$ concentrations (not shown) do not 


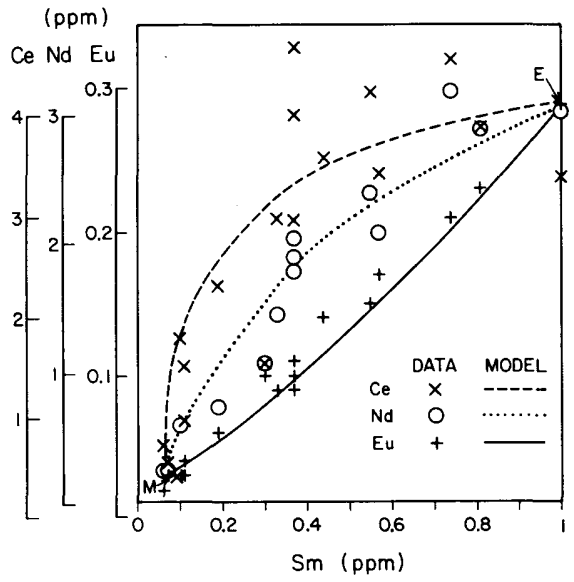

FIG. 5.-REE concentrations of peridotite nodules from Hoggar, Algeria (Dupuy et al. 1986). Concentrations of $\mathrm{Ce}, \mathrm{Nd}$, and $\mathrm{Eu}$ are plotted against $\mathrm{Sm}$ concentration (concentrations along the $y$ axis were plotted so that end member samples plot at approximately the same position). The data array for $\mathrm{Ce}$ and, to a lesser degree, $\mathrm{Nd}$ deviate from a straight line expected for simple mixing. The concave downward patterns fit the predictions of the chromatographic model (see text). Shown for reference are the results of a model calculation for column parameters and $K_{d}$ values from figure 4 . Matrix composition, $M$, is that of the most depleted nodules; melt composition is in equilibrium with the most enriched samples, $E$.

correlate with $\mathrm{Sm}$; this could reflect the fact that the fronts of the more compatible elements did not reach most of the nodules, in which case their concentrations would still reflect older melting events (Dupuy et al. 1986).

Lacking any information about the spatial relations of the nodules prior to eruption, we cannot estimate the size of the chromatographic column that could have produced the patterns shown in figure 5 . These patterns could be the result of a large-scale column of the kind discussed above, or of a smallerscale chromatographic process operating outward from walls of dikes that intersected the source region. Melt tapped by the matrix may have contributed to the high REE concentrations of the suite (as suggested by petrographic data; Dupuy et al. 1986). However, the correlation of the deviation from a straight mixing line with the element incompatibility strongly suggests the operation of a chromatographic process in the source region of the Hoggar peridotitic nodules. b. Island arc magmatism: matrix crossfeeding. An obvious environment for application of the chromatographic concept is in the source regions of island arc magmas. Fluids generated in the upper parts of subducting slabs are thought to interact extensively with the overlying mantle as they flow through it. Melts which form either in the subducted slab or in the mantle wedge above it can percolate upward and interact with overlying mantle material. The chromatographic column is a useful point of reference for thinking about the nature of this interaction. A number of authors (e.g., Nicholls and Ringwood 1973; Marsh and Kantha 1978; Mysen 1979) have anticipated aspects of the consequences of this process, and Myers et al. (1985) discuss an example where they think they can see petrochemical features that have time dependencies similar to those that might be expected in the output of a chromatographic system.

In an important respect, the situation above a subducting slab will differ from the simple case upon which we have been focusing. Suppose that the source region for the fluids or melts is fixed relative to the island arc (fig. 6). The mantle wedge convects as the fluids percolate upward through it. In the context of our chromatographic column, this amounts to a continuous replenishment of the column matrix. In this section, we examine some of the consequences of this lateral movement of material into and out of the chromatographic column and suggest how this may relate to the compositions of magmas delivered to island arc volcanoes.

Consider a simple, two-dimensional model of our ideal column (local equilibrium, negligible dispersion). A column of length $L$ and width $W$ (fig. 6) is cross-fed by the convective flow in the mantle wedge. Fluids penetrate the column from below and percolate upward with a velocity $\bar{V}_{p}$. Fresh matrix is introduced on the left-hand side and passes through the column with a velocity $\bar{V}_{\mathrm{s}}$. Concentration fronts migrate upward while at the same time they are carried sideward and downward with the matrix. A steady-state situation is reached after the matrix migrates the whole width of the column or when the concentration front reaches the top of the column. As shown in detail in Appendix B, fronts of incompatible elements are carried only small 

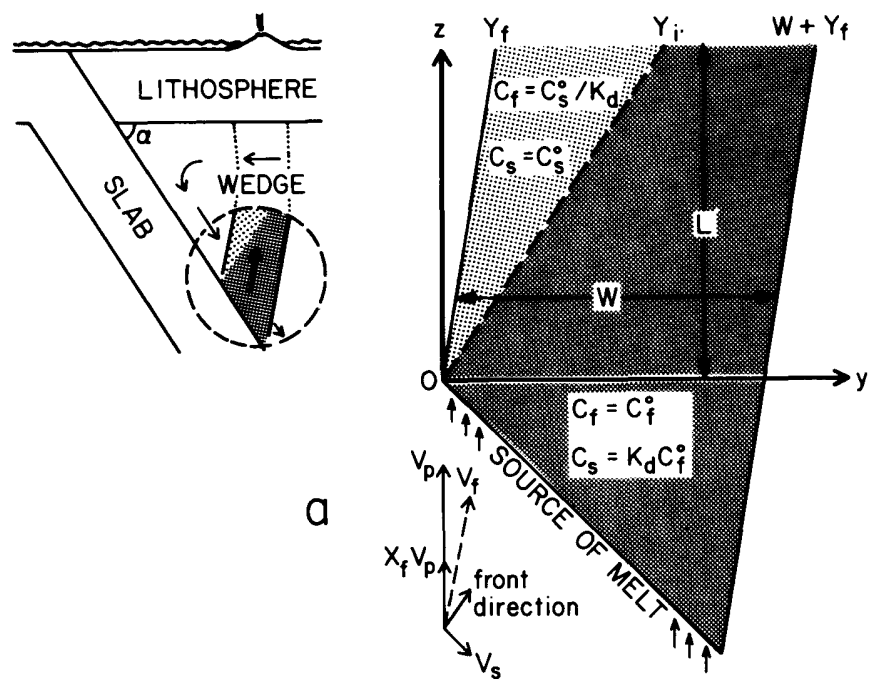

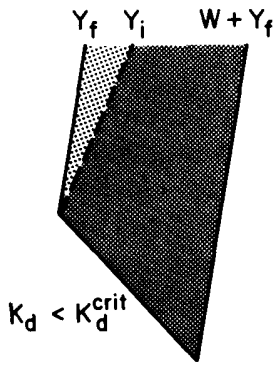

b

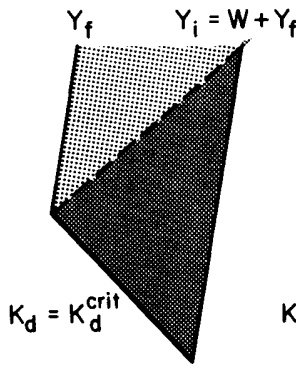

C

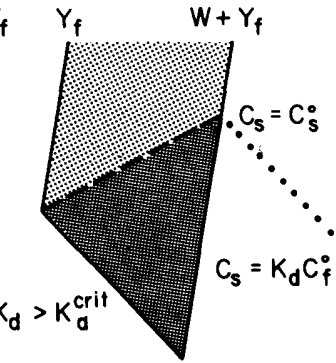

d

FIG. 6. - Schematic representation of matrix cross-feeding below island arcs. (a) Melts which form in the subducted slab or in the wedge above it percolate upward through a column of wedge material. Fresh material is introduced by convection. Melt percolates upward at velocity $\bar{V}_{p}$ and is moved with the matrix which is fed in at velocity $\bar{V}_{s}$. Melt that originates at the lower left corner of the column (0) emerges at $Y_{f}$. A concentration front of a trace element $i$ travels at a lower velocity, $X_{f} \bar{V}_{p}$, is carried further by the matrix, and emerges at $Y_{i}$. Melts emerging to the left of $Y_{i}$ have a composition $C_{f}=C_{s}^{\circ} / K_{d}$; those emerging to the right retain their initial composition, $C_{f}^{\circ}$. The position of $Y_{i}$ depends on the element compatibility, and three cases are illustrated: (b) An incompatible element. Most of the melt emerges with the same concentration as in melt introduced into the base of the column. $(c) K_{d}=K_{d}^{\text {crit }} . Y_{i}$ coincides with the right edge of the column. The concentration and isotopic composition of this element in melts emerging at the top is in equilibrium with the matrix and does not reflect the original source region. $(d)$ A compatible element. Its concentration in the melt is as in (c). Matrix coming out of the column is zoned with respect to this element. At the lower part it is in equilibrium with the melt introduced at the bottom, $C_{s}=K_{d} C_{f}^{\circ}$; in the upper part the matrix has not been changed by interaction with melt.

distances with the matrix, and most of the fluids pass the column unaltered (fig. $6 b$ ). Fronts of compatible elements are carried through the entire column width, and the fluid emerging from the top of the column is completely altered and is in equilibrium with the original matrix composition (fig. 6d).

If, as a first approximation, the subduction angle, $\alpha$, is taken to be zero, the critical $K_{d}$ value, above which the composition of a certain element in the fluid is controlled by the wedge composition only and does not reflect the original fluid composition, is shown in Appendix B to be:

$$
K_{d}^{\text {crit }} \approx \frac{W V_{p} \phi}{L V_{s}}
$$


$W V_{p} \phi=G$ is the flux of melt through the two-dimensional column, and should be equal to the rate of growth of the arc. A recent estimate of this rate (Reymer and Schubert 1984) is $30 \mathrm{~km}^{2} / \mathrm{Ma}$, so for a choice of $L=10 \mathrm{~km}$ and $V_{s}=3 \mathrm{~cm} /$ year, the critical value is $K_{d}^{\text {crit }} \sim 0.1$. In other words, all elements with $K_{d}>0.1$ will emerge from the mantle column in equilibrium with the initial wedge composition. Only more incompatible elements will reflect contributions of other sources, i.e., the subducted oceanic crust or sediments. The choice of $L=10 \mathrm{~km}$ (i.e., the distance over which melt percolates along grain boundaries) is somewhat arbitrary. Larger values would lead to decreases in $K_{d}^{\text {crit }}$ and to a greater imprint of the mantle wedge on the compositions of erupted magmas.

If the slope of the subduction zone is included in the calculation (equation B7), $K_{d}^{\text {crit }}$ may be an order of magnitude lower than the value given in equation (B8) for reasonable choices of parameters. Our analysis shows that a $10-\mathrm{km}$ column can significantly affect the trace element contents of melts that percolate through the wedge overlying the subducting slab. Elements such as the heavy and intermediate REE would reflect only the composition of the mantle wedge. Hf or $\mathrm{Nd}$ isotopes would reflect only slight contributions from other sources. Fronts of more incompatible systems such as $\mathrm{Pb}$ and, to a lesser degree, $\mathrm{Sr}$ do pass through the column, and their isotopic composition may reflect contributions from the subducted oceanic crust or sediments. The same is true for incompatible element concentrations such as $\mathrm{Cs}$ or $\mathrm{Ba}$.

Based on our analysis, the contribution of the subducted oceanic crust and sediments is expected to be large for arcs with high ratios of growth rate over subduction velocities $(G /$ $V_{s}$ ) and with shallow subduction angles (equation B7). Though other parameters must also affect the contribution of the subducted sediment component, it is interesting to note that the Lesser Antilles, where large contributions from subducted sediments have been suggested (White and Patchett 1984), is characterized by extremely high $G / V_{s}$ ratio (Reymer and Schubert 1985) and relatively shallow subduction angles $\left(45^{\circ}\right.$; Molnar and Atwater 1978) compared with other arcs.

c. Comagmatic alkaline basalts and tho- leiites. The nature of the relationship between comagmatic tholeiitic and alkaline basalts remains one of the most enigmatic problems in petrogenesis. One possible explanation is that alkaline magmas evolve from tholeiitic liquids by interaction with the peridotitic wallrocks that they traverse en route to the surface (e.g., Harris 1957; Green and Ringwood 1967). Recent isotopic and trace element data of tholeiitic and alkaline suites from Hawaiian volcanoes (e.g., Chen and Frey 1985) as well as from southeastern Australia (McDonough et al. 1985) indicate that both suites reflect the mixing of melts from at least two sources. Chen and Frey have suggested a model in which a tholeiitic melt formed by high degree of partial melting of an undepleted "plume" source is physically mixed with variable quantities of melt formed by low degree of partial melting of a depleted mantle similar in composition to the source regions of mid-ocean ridge basalts (MORB).

It is possible to produce similar effects by letting the melts of the plume source penetrate and percolate through an initially unmolten column of MORB source composition. The characteristics of the incipient partial melting of the MORB source reservoir are then "injected"' through reaction and ionexchange, rather than through physical mixing of magmas. The column can "mix" the two end members in all needed proportions. The resultant REE patterns would be similar to those of figures $2 b$ and $3 b$. Though details would depend on the specific parameters chosen, early melts have trace element characteristics similar in important respects to Hawaiian alkaline basalts (i.e., REE patterns similar to small degrees of partial melting of the column matrix, isotopic signature dominated by the contribution of the MORB source end member). As more and more melt percolates through the column and its ability to affect melt composition is diminished, the melt composition gradually changes toward that of the tholeiitic melt being continuously introduced at the base of the column. Thus, as anticipated long ago by Harris and by Green and Ringwood, wallrock interaction is indeed capable of producing melts similar to alkali olivine basalts, at least with respect to their trace element characteristics. It is not clear that the incipient melt of the depleted 
column matrix has the undersaturation with respect to silica that is the defining characteristic of the alkaline suite.

Such a scenario must, however, be an extreme simplification of any possible natural plumbing system. While it may be applied to the early alkaline lavas of a Hawaiian volcano (e.g., Loihi Seamount; Moore et al. 1982) or to the formation of small alkaline volcanic centers, it clearly fails to explain certain major features of the later phases of Hawaiian volcanism. In particular, during the transition from the early alkaline stage to the main tholeiitic stage, the simple, static column is all used up. Thus the tholeiites must be, in the context of this scenario, the unmodified melt of the plume source. For this reason, we cannot easily account for the variability in trace element and isotopic composition observed in tholeiites of different Hawaiian volcanoes. More obviously, we cannot produce the enrichment of incompatible elements observed in the late transitional and alkaline phases.

In order to produce the observed sequence and to explain the late phases of Hawaiian volcanism, we must invoke the introduction of fresh column material. One mechanism for introducing fresh matrix is through crossfeeding by mantle convection (fig. 7), similar to the case presented for island arcs. During the shield-building tholeiitic stage, the high
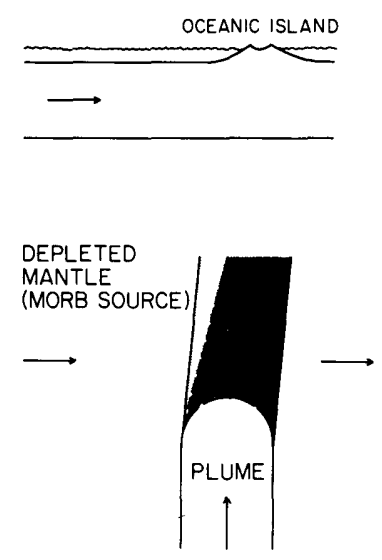

Fig. 7.-Schematic representation of crossfeeding below an oceanic island. Melt rises from a melting plume and percolates through a region of depleted mantle above the plume. Mantle convection cross-feeds fresh column material into the column region so that a steady-state situation evolves, analogous to that presented in figure 6. flux of plume material overcomes the replenishment of the matrix, and melt composition is barely changed from its initial tholeiitic composition. During the later stages the plume flux is weaker and the contribution of the cross-fed MORB source-like matrix is more pronounced. Using equation (B9) of Appendix B, and the estimated volcanic fluxes of Feigenson and Spera (1981), critical aspects of the geochemistry of the observed sequences of Hawaiian lavas can be reproduced by ion exchange processes. In particular, we can reproduce the same gross characteristics that Chen and Frey (1985) achieved when they postulated that during the alkalic stage the contribution of the MORB sourcelike matrix is of higher proportion and its composition is closer to that produced by incipient melting. Still, we cannot readily explain the variability of tholeiitic basalt compositions of different centers, since the flux of the cross-fed matrix would not be sufficient to alter significantly the composition of the plume-derived melts. Richter and McKenzie (1984) encountered a similar problem when they considered another model for the volcano plumbing system. This difficulty seems to be independent of the plumbing system chosen or the mixing mechanism of the two end members used. This, along with recent isotopic studies (e.g., Stille et al. 1983; Staudigel et al. 1984; Hegner et al. 1986), may suggest the need for additional components to account for the variability in trace elements and isotopic composition of Hawaiian tholeiites.

\section{CONCLUSIONS}

As magmas rise from their source regions toward the surface, it is inevitable that they will traverse regions of the mantle and crust with which they are not in equilibrium; to the extent that time and the intimacy of their physical contact permit, the melts and country rocks will interact chemically. In this paper, we have suggested that regions of the mantle can be treated as chromatographic columns and that, as melts and other fluids flow through these regions, aspects of their chemical interaction can be modeled in terms of a simple ion-exchange process. The implications for trace element systematics are straightforward: The composition of melt emerging from the top of the column evolves 
from close to that of the incipient melt of the column matrix toward that of the melt introduced into the base of the column. The rate of evolution is faster in the incompatible than in the compatible elements and as a result the abundance ratios of elements of different compatibilities can vary considerably with time.

If diffusion and other dispersive processes in the melt are negligible and if exchange between melt and solid rock is rapid, extreme fractionations may occur, and the change from initial to final concentration for each element can be through an abrupt concentration front. The abruptness of this change may be softened by dispersive processes within the column, by gradual change with time of the composition of the melt flowing into the column, or by integrating and mixing the column output.

If the matrix material is not replenished, the chromatographic process is a transient phenomenon. However, in some geological situations (e.g., under island arcs and oceanic islands), fresh matrix may be fed continuously into the column, leading to the evolution of a steady state.

We have demonstrated that aspects of the geochemistry of ultramafic rocks and comagmatic alkaline and tholeiitic magmas might be explained by the operation of chromatographic columns. This is not sufficient to prove that such processes did play a role, since combinations of other petrogenetic processes could undoubtedly produce similar petrological characteristics. We emphasize that we consider it extremely unlikely that chromatographic columns will operate exclusive of other processes. In particular, if melt and matrix are not in thermal and major element equilibrium, crystal fractionation and/or melting of the matrix must accompany the ion-exchange processes upon which we have focused. In addition, spatial and temporal variations in source composition and in the degree of partial melting will influence the compositions of melts introduced into our hypothetical columns. Mixing, assimilation, crystal fractionation, and other magma chamber processes will typically place their marks upon the output of such columns.

Nevertheless, the raw output of a mantle chromatographic column should, according to our analysis, be easy to recognize, and though its characteristic fingerprints may be masked or mimicked by other processes, they should be identifiable, if present, through study of the temporal evolution of trace element systematics of volcanic suites, especially if elements across a wide range of compatibilities are examined.

Acknowledgments.-We have benefited from discussions with D. Scott, D. Stevenson, B. Hager, F. Richter, B. Marsh, and G. J. Wasserburg, and from reviews by M. Seitz, C. Langmuir, and F. Richter. This work has been supported by NASA Grant NAG 9-105 to E. Stolper and NSF Grant EAR-84-18353 to D. Stevenson. Caltech Division of Geological and Planetary Sciences contribution number 4350 .

\section{APPENDIX A: THE NUMERICAL SOLUTION}

If dispersion in the fluid is neglected so that mass transport into and out of the elemental volume is by advection only, the evolution of the trace elements in the column can be modeled using the STOP-GO algorithm (Sweed and Wilhelm 1969). The advection is represented by the GO phase in which the fluid is advanced a distance $\Delta z$. Then during the STOP phase the stationary fluid interacts with the matrix for time $\Delta t=\Delta z / V_{f}$.

Diffusion in the spherical grains is governed by:

$\frac{\partial C_{r}(z, r, t)}{\partial t}=D_{s}\left[\frac{\partial^{2} C_{r}(z, r, t)}{\partial r^{2}}+\frac{2}{r} \frac{\partial C_{r}(z, r, t)}{\partial r}\right]$

where $C_{r}(z, r, t)$ is the concentration at radius $r$ within a grain located at distance $z$ from the bottom of the column at time $t$. The boundary conditions are determined by the spherical symmetry and the following assumptions: (a) Grain surfaces are always in equilibrium with the fluid:

$$
C_{r}(z, a, t)=K_{d} C_{f}(z, t)
$$

(b) The fluid is of limited volume so its concentration is related to the average concentration in the grain, $C_{s}(z, t)$, by:

$$
\begin{aligned}
\phi \rho_{f} \frac{\partial C_{f}(z, t)}{\partial t}= & -(1-\phi) \rho_{s} \frac{\partial C_{s}(z, t)}{\partial t} \\
= & -(1-\phi) \rho_{s} \frac{3}{a^{3}} \\
& \cdot \frac{\partial}{\partial t}\left[\int_{o}^{a} C_{r}(z, r, t) r^{2} d r\right]
\end{aligned}
$$

(c) The fluid is homogeneous at all times; this assumption is justified because diffusion in the fluid is 
six to seven orders of magnitude faster than that in the solid.

Equation (A1) was solved numerically using the Crank-Nicolson algorithm. We chose to describe the change in fluid composition by equation (A3), rather than by Fick's first law, since the numerical evaluation of the integral is more accurate than the evaluation of $\partial C_{r} / \partial r$ at $r=a$, where a singularity may exist. Typically we used $L / \Delta z=20, a / \Delta r=$ 75 , and updated the fluid concentration five times during each of the STOP phases. The accuracy of the numerical technique was checked by comparing the numerical and the analytical solutions for the case of static fluid and by comparing solutions obtained using different grid sizes.

The results of some sample calculations are presented in figure $3 a$, and are characterized by (a) faster migration of the fronts compared with the equilibrium case, and (b) different amounts of dispersion for fronts of different elements. The numerical solution is a function of two independent, dimensionless parameters: $X_{f}$, and $D_{s} t_{d} a^{2}$ (which is the ratio of the advective $\left(t_{c}\right)$ and diffusive $\left(a^{2} / D\right)$ time scales).

An approximate expression for the front position in time that involves these two parameters and that will simplify application of our treatment to situations other than those we have considered may be obtained by considering the following situation: Ahead of its front, a trace element in the fluid is in equilibrium with the matrix. Behind the front, fluid concentration is constant, $C_{f}^{\circ}$, and the matrix composition is controlled by a simple diffusion law (Glueckauf 1955):

$$
\frac{\partial C_{s}}{\partial t}(z, t)=\alpha\left(C_{f} K_{d}-C_{s}\right)
$$

where $\alpha$ is a parameter that includes the diffusion coefficient and other column parameters. Assuming that all fronts are sharp, and that to the first order their velocity may be taken to be constant, we can solve for $C_{s}(z, t)$ and calculate the average concentration in the solid behind the front:

$$
\begin{aligned}
\bar{C}_{s}(t) & =\frac{1}{z_{\text {front }}} \int_{o}^{z_{\text {front }}} C_{s}(z, t) d z \\
& =K_{d} C_{f}^{\circ}\left[1-\frac{1-\exp (-\alpha t)}{\alpha t}\right]
\end{aligned}
$$

Repeating the mass balance calculation (equation 4), we obtain

$$
\frac{z}{Z}=\frac{\phi \rho_{f}}{\phi \rho_{f}+(1-\phi) \rho_{s} K_{d}\left[1-\frac{1-\exp (-\alpha t)}{\alpha t}\right]}
$$

Fitting equation (A6) against the numerical results, we obtain very good agreement (better than $7 \%$ ) using:

$$
\begin{aligned}
\alpha & =\frac{4 \pi D_{s}}{a^{2}} \cdot \frac{1-\phi}{\phi} \frac{\rho_{s}}{\rho_{f}} K_{d} \\
& =\frac{4 \pi D_{s}}{a^{2}} \frac{1-X_{f}}{X_{f}}
\end{aligned}
$$

for $0.01<D_{s} t / a^{2}<1$ and $0.1<(1-\phi) \rho_{s} K_{d} / \phi \rho_{f}=$ $\left(1-X_{f}\right) / X_{f}<2$. The physical situation described by equation (A6) is that of a concentration front which moves with the melt $\left(V_{\text {front }}=V_{f}\right)$ at $t=0$ and relaxes to the equilibrium velocity $\left(V_{\text {front }}=\right.$ $V_{f} X_{f}$ ) for long times. The decay time is shorter for compatible elements than for incompatible ones.

The shape of the dispersed front can be approximated by equations of the form of equation (11) provided that: $z_{\text {front }}$ is calculated using equations (A6) and (A7); an additional term is added in order to ensure that at the fluid front $\left(z=V_{f} t\right)$ fluid concentration decays to the equilibrium value, $C_{f}=$ $C_{s}^{\circ} / K_{d}$; and the diffusion coefficient of the fluid, $D_{f}$, is replaced by:

$$
" D "=\frac{a^{2} V_{f}^{2}}{4 \pi D_{s}} X_{f}\left(1-X_{f}\right) .
$$

Glueckauf (1955) suggested a similar expression for " $D$," but did not consider the faster rate of migration of the fronts compared with the equilibrium case. In a given column, elements with $X_{f} \sim 0.5$ $\left(K_{d} \sim \phi\right)$ will be dispersed by the largest amount.

\section{APPENDIX B: MATRIX CROSS-FEEDING}

Consider a simple model where fluid is introduced at the bottom of a column of width $W$ (fig. 6 ) and matrix is fed in a uniform velocity at an angle $\alpha$ to the horizontal. Such a column reaches a steady state for a certain element

$$
\left(\frac{\partial C_{f}}{\partial t}\right)_{y, z}=\left(\frac{\partial C_{s}}{\partial t}\right)_{y, z}=0
$$

either when the concentration front reaches the top of the column or after the matrix migrates across the full column width. If dispersive processes are negligible, then a simplified form of equation (1a) describes the mass balance of the advecting fluxes of trace elements by fluid and matrix flowing through the column:

$$
\phi \rho_{f} \bar{V}_{f} \bar{\nabla} C_{f}=-(1-\phi) \rho_{s} \bar{V}_{s} \bar{\nabla} C_{s} .
$$


Assuming instantaneous local equilibrium, this becomes:

$$
X_{f} \bar{V}_{f} \bar{\nabla} C_{f}=-\left(1-X_{f}\right) \bar{V} \bar{s} C_{f}
$$

$V_{f}$ is the vector sum of the percolation velocity relative to the static matrix $V_{p}$ and the matrix velocity $V_{s}$. Separating the velocities into their $y$ and $z$ components, substituting into equation (B3), and rearranging yields:

$$
\frac{\partial C_{f}}{\partial z}=-\frac{V_{s} \cos \alpha}{X_{f} V_{p}-V_{s} \sin \alpha} \frac{\partial C_{f}}{\partial y},
$$

which means that $C_{f}$ is constant along lines of slope

$$
\frac{\partial z}{\partial y}=\frac{X_{f} V_{p}-V_{s} \sin \alpha}{V_{s} \cos \alpha}
$$

and in particular the position of the concentration front $\left[C_{f}=C_{f}^{\circ}+0.5\left(C_{f}^{\circ} / K_{d}-C_{f}^{\circ}\right)\right]$ also lies in this direction.

This result can also be visualized in the following way: from the time the wedge material starts its way across the column, a flux of fluid is penetrating it. While the wedge moves a distance $d y=$ $V_{f} \cos \alpha d t$, the melt percolates upward by $\left(V_{p}-\right.$ $\left.V_{s} \sin \alpha\right) d t$, and the front, being slower, migrates a distance $d z=\left(X_{f} V_{p}-V_{s} \sin \alpha\right) d t$. The combined effect is the same as given by equation (B5).

Equation (B5) can be used to calculate the front position at the top of the column ( $Y_{i}$ in fig. 5). If $Y_{i}$ $>Y_{f}+W$, where $Y_{f}$ is the displacement of the fluid itself along the $y$ direction and $W$ the width of the column, then the front does not reach the top of the column. All fluid coming out is in equilibrium with the matrix and has $C_{f}=C_{s}^{\circ} / K_{d} . Y_{i}$ depends on $X_{f}$ (equation B5) and hence on $K_{d}$. Fronts of incompatible elements may pass the column, but above a certain degree of compatibility, no matter what the input is, the output is characterized by the matrix only.

The critical $K_{d}$ value can be calculated from:

$$
\begin{aligned}
Y_{i}-Y_{f}= & \frac{L V_{s} \cos \alpha}{X_{f} V_{p}-V_{s} \sin \alpha} \\
& -\frac{L V_{s} \cos \alpha}{V_{p}-V_{s} \sin \alpha}<W
\end{aligned}
$$

which yields

$$
\begin{aligned}
K_{d}^{\text {crit }}= & \frac{W V_{p} \phi \rho_{f}}{L V_{s}(1-\phi) \rho_{s}} \\
& \cdot \frac{\left(1-\frac{V_{s}}{V_{p}} \sin \alpha\right)^{2}}{\cos \alpha+\frac{W}{L} \sin \alpha\left(1-\frac{V_{s}}{V_{p}} \sin \alpha\right)}
\end{aligned}
$$

If, as a first approximation, the subduction angle, $\alpha$, is taken to be zero, then:

$$
K_{d}^{\text {crit }}<\frac{W V_{p} \phi \rho_{f}}{L V_{s}(1-\phi) \rho_{s}} \approx \frac{W V_{p} \phi}{L V_{s}}=\frac{G}{L V_{s}}
$$

$G=W V_{p} \phi$ is the flux of melt through the twodimensional column. In the case of the island arc, this flux is equal to the rate of growth of the arc per unit length of arc. In the three-dimensional case of hot spot volcanism (i.e., Hawaii), the column width and length have to be replaced by cross-sections in order to relate $K_{d}^{\text {crit }}$ to the rate of growth.

$$
K_{d}^{\mathrm{crit}}=\frac{G^{\prime}}{L W V_{s}}
$$

The incompatible element composition in melts emerging from the column is only partially affected by the matrix contribution. Averaging the column output over the entire width, the average concentration of elements with $K_{d}<K_{d}^{\text {crit }}$ is

$$
C_{f}=\frac{C_{s}^{\circ}}{K_{d}}\left(\frac{Y_{i}-Y_{f}}{W}\right)+C_{\mathrm{f}}^{\circ}\left(1-\frac{Y_{i}-Y_{f}}{W}\right) .
$$

From equations (B6) and (B8) it follows that

$$
\left(Y_{i}-Y_{f}\right) / W \approx K_{d} / K_{d}^{\text {crit }}
$$

and

$$
C_{f} \approx C_{f}^{\circ}+\frac{C_{s}^{\circ}-K_{d} C_{f}^{\circ}}{K_{d}^{\mathrm{crit}}}
$$

for incompatible elements with $K_{d}<K_{d}^{\text {crit }}$.

\section{REFERENCES CITED}

Bear, J., 1972, Dynamics of Fluids in Porous Media: New York, American Elsevier, 764 p.

Boettcher, A. L., and O'Neil, J. R., 1980, Stable isotope, chemical, and petrographic studies of high-pressure amphiboles and micas: evidence for metasomatism in the mantle source regions of alkali basalts and kimberlites: Am. Jour. Sci., v. 280A, p. 584-621.
Chen, C. Y., and Frey, F. A., 1985, Trace element and isotopic geochemistry of lavas from Haleakalea volcano, East Maui, Hawaii: implications for the origin of Hawaiian basalts: Jour. Geophys. Res., v. 90, p. 8743-8768.

DePaolo, D. J., and Wasserburg, G. J., 1976, Nd isotopic variations and petrogenetic models: Geophys. Res. Letters, v. 3, p. 249-252. 
Dulien, F. A. L., 1979, Porous Media Fluid Transport and Pore Structure: New York, Academic Press, $396 \mathrm{p}$.

Dupuy, C.; Dostal, J.; Dautria, J. M.; Girod, M., 1986, Geochemistry of spinel peridotite inclusions in basalts from Hoggar, Algeria: Jour. African Earth Sci., v. 5, p. 209-215.

Feigenson, M. D., and Spera, F. J., 1981, Dynamical model for temporal variation in magma type and eruption interval at Kohala volcano, Hawaii: Geology, v. 9, p. 531-533.

FreER, R., 1981, Diffusion in silicates minerals and glasses: a data digest and guide to literature: Contrib. Mineral. Petrol., v. 76, p. 440-454.

Frey, F. A.; Green, D. H.; and Roy, S. D., 1978, Integrated models of basalt petrogenesis: a study of quartz tholeiites to olivine melilites from southern Australia utilizing geochemical and experimental petrological data: Jour. Petrol., v. 19, p. $463-513$.

-; Suen, C. J.; and Stockman, H. W., 1985, The Ronda high temperature peridotite: geochemistry and petrogenesis: Geochim. Cosmochim. Acta, v. 49, p. 2469-2492.

Glueckauf, E., 1955, Theory of chromatography: Trans. Faraday Soc., v. 51, p. 34-44.

Green, D. H., and Ringwood, A. E., 1967, The genesis of basaltic magmas: Contrib. Mineral. Petrol., v. 15, p. 103-190.

HARRIS, P. J., 1957, Zone refining and the origin of potassic basalts: Geochim. Cosmochim. Acta, v. 12, p. 195-208.

Hart, S. R., and Allegre, C. J., 1980, Trace element constraints on magma genesis, in HARGraves, R. B., ed., Physics of Magmatic Processes: New Jersey, Princeton University Press, p. 121-159.

Hegner, E.; Unruh, D.; and Tatsumoto, M., 1986, Nd-Sr-Pb isotope constraints on the sources of West Maui volcano, Hawaii: Nature, v. 319 , p. $478-480$.

HofmanN, A. W., 1972, Chromatographic theory of infiltration metasomatism and its application to feldspars: Am. Jour. Sci., v. 272, p. 69-90.

$\longrightarrow, 1984$, Mantle evolution by crustal recycling or by mantle metasomatism? (abs.): Terra Cognita, v. 4, p. 82.

IRving, A. J., 1980, Petrology and geochemistry of composite ultramafic xenoliths in alkalic basalts and implications for magmatic processes within the mantle: Am. Jour. Sci., v. 280A, p. 389-426.

KorzhinskiI, D. S., 1970, Theory of Metasomatic Zoning (translated by Jean Agrell): Oxford, Clarendon Press, 162 p.

Magaritz, M., and Hofmann, A. W., 1978, Diffusion of $\mathrm{Eu}$ and $\mathrm{Gd}$ in basalt and obsidian: Geochim. Cosmochim. Acta, v. 42, p. 847-858.

Marsh, B. M., and Kanta, L. H., 1978, On the heat and mass transfer from an ascending magma: Earth Planet. Sci. Letters, v. 39, p. 435443.

McDonough, W. R.; McCulloch, M. T.; and Sun, S. S., 1985, Isotopic and geochemical systematics in Tertiary-Recent basalts from southeastern Australia and implications for the evolution of the sub-continental lithosphere: Geochim. Cosmochim. Acta, v. 49, p. 2051-2068.
McKenzie, D. P., 1984, The generation and compaction of partial melts: Jour. Petrol., v. 25, p. $713-765$.

- 1985, The extraction of magma from the crust and mantle: Earth Planet. Sci. Letters, v. 74, p. 81-91.

Menzies, M.; Kempton, P.; and Dungan, M., 1985 , Interaction of continental lithosphere and asthenospheric melts below Jeronimo volcanic field, Arizona, U.S.A.: Jour. Petrol., v. 26, p. 663-693.

Molnar, P., and Atwater, T., 1978, Interarc spreading and cordilleran tectonics as alternates related to the age of subducted oceanic lithosphere: Earth Planet. Sci. Letters, v. 41, p. 330340.

Moore, J. D.; Clague, D. A.; and Normark, W. R., 1982, Diverse basalt types from Loihi Seamount, Hawaii: Geology, v. 10, p. 88-92.

Myers, J. D.; Marsh, B. D.; and Sinha, A. K., 1985, Strontium isotopic and selected trace element variations between two Aleutian volcanic centers (Adak and Atka): implications for the development of arc volcanic plumbing systems: Contrib. Mineral. Petrol., v. 91, p. 221-234.

MySEN, B. O., 1979, Trace element partitioning between garnet peridotite minerals and water rich vapor: experimental data from 5 to 30 kbar: Am. Mineral., v. 64, p. 274-287.

Nicholls, I. A., and Ringwood, A. E., 1973, Effect of water on olivine stability in tholeiites and production of silica-saturated magmas in the island arc environment: Jour. Geology, v. 81, p. 285-300.

Norton, D., and TAYlor, H. P., JR., 1979, Quantitative simulation of the hydrothermal systems of crystallizing magmas on the basis of transport theory and oxygen isotope data: An analysis of the Skaergaard intrusion: Jour. Petrol., v. 20, p. 421-486.

Pallister, J. A., and Knight, R. J., 1981, Rare earth element geochemistry of the Samail ophiolite near Ibra, Oman: Jour. Geophys. Res., v. 86, p. 2673-2697.

Prinzhofer, A., and Allegre, C. J., 1985, Residual peridotite and the mechanism of partial melting: Earth Planet. Sci. Letters, v. 74, p. 251-265.

Quick, J. E., 1981, Petrology and petrogenesis of the Trinity peridotite: an upper mantle diapir in the eastern Klamath mountains, northern California: Jour. Geophys. Res., v. 86, p. 1183711863.

Reymer, A., and Schubert, G., 1984, Phanerozoic addition rates to the continental crust and crustal growth: Tectonics, v. 3, p. 63-77.

RIBE, N. M., 1985, The generation and composition of partial melts in the earth's mantle: Earth Planet. Sci. Letters, v. 73, p. 361-376.

RiCHTER, F. M., 1986, Simple models for trace element fractionation during melt segregation: Earth Planet. Sci. Letters, v. 79, p. 333-344.

, and McKenzIE, D., 1984, Dynamical models for melt segregation from deformed matrix: Jour. Geology, v. 92, p. 729-740.

Scott, D. R., and Stevenson, D. J., 1984, Magma solitons: Geophys. Res. Letters, v. 11, p. 11611164. 
, and Stevenson, D., 1986, Magma ascent by porous flow: Jour. Geophys. Res., v. 91, p. 9283-9296.

Shaw, H. R.; Tucson, E. D.; and Barger, K. E., 1980 , Volcanic periodicity along the Hawaiian Emperor chain: Am. Jour. Sci., v. 280A, p. 667708.

Sneeringer, M.; Hart, S. R.; and Shimizu, N., 1984, Strontium and samarium diffusion in diopside: Geochim. Cosmochim. Acta, v. 48, p. 1589-1608.

Staudigel, H.; Zindler, A.; Hart, S. R.; Leslie, T.; Chen, C.-Y.; and Clague, D., 1984, The isotope systematics of a juvenile intraplate volcano: $\mathrm{Pb}, \mathrm{Nd}$, and $\mathrm{Sr}$ isotope ratios of basalts from Loihi seamount, Hawaii: Earth Planet. Sci. Letters, v. 69, p. 13-29.

Stille, P.; Unruh, D. M.; and Tatsumoto, M., $1983, \mathrm{~Pb}, \mathrm{Sr}, \mathrm{Nd}$ and $\mathrm{Hf}$ isotopic evidence of multiple sources for Oahu, Hawaii basalts: $\mathrm{Na}$ ture, v. 304, p. 25-29.

StolPer, E.; Walker, D.; Hager, B. D.; and HAYs, J. F., 1981, Melt segregation from partially molten source regions: the importance of melt density and source region size: Jour. Geophys. Res., v. 86, p. 6261-6271.
Stosch, H.-G., and SeCK, H. A., 1980, Geochemistry and mineralogy of two spinel peridotite suites from Dreiser Weiher, West Germany: Geochim. Cosmochim. Acta, v. 44, p. 457-470.

Sweed, N. H., and Wilhelm, R. H., 1969, Parametric pumping: separation via direct thermal mode: Inc. Eng. Chem. Fundam., v. 8, p. 221-231.

Walker, D.; Stolper, E. M.; and Hays, J. F., 1978, A numerical treatment of melt/solid segregation: size of the eucrite parent body and stability of the terrestrial low-velocity zone: Jour. Geophys. Res., v. 83, p. 6005-6013.

WARREN, P. H., and WASSON, J. T., 1979, The origin of KREEP: Rev. Geophys. Space Phys., v. 17 , p. 73-88.

WATSON, E. B., 1982, Basalt contamination by continental crust: some experiments and models: Contrib. Mineral. Petrol., v. 80, p. 73-87.

White, W. M., and Patchett, J., 1984, Hf-Nd-Sr isotopes and incompatible element abundances in island arcs: implications for magma origins and crust-mantle evolution: Earth Planet. Sci. Letters, v. 67, p. 167-185. 